OPEN ACCESS

Edited by:

Rajeev K. Singla,

Sichuan University, China

Reviewed by:

Yang Liu,

Peking University Third Hospital, China

Manoj Kumar Sabnani,

University of Texas at Arlington,

United States

*Correspondence:

Md. Sahab Uddin

msu.neuropharma@gmail.com

tORCID:

Md. Sahab Uddin https://orcid.org/0000-0002-0805-

7840

Specialty section:

This article was submitted to

Ethnopharmacology,

a section of the journal

Frontiers in Pharmacology

Received: 30 April 2021 Accepted: 09 August 2021 Published: 27 August 2021

Citation:

Uddin MS, Kabir MT, Mamun AA, Sarwar MS, Nasrin F, Emran TB, Alanazi IS, Rauf A, Albadrani GM,

Sayed AA, Mousa SA and Abdel-Daim MM (2021) Natural Small Molecules Targeting NF- $k B$ Signaling in Glioblastoma.

Front. Pharmacol. 12:703761. doi: 10.3389/fphar.2021.703761

\section{Natural Small Molecules Targeting NF-kB Signaling in Glioblastoma}

\author{
Md. Sahab Uddin ${ }^{1,2 * t}$, Md. Tanvir Kabir ${ }^{3}$, Abdullah Al Mamun ${ }^{4}$, Md. Shahid Sarwar ${ }^{5}$, \\ Fatema Nasrin ${ }^{6,7}$, Talha Bin Emran ${ }^{8}$, Ibtesam S. Alanazi ${ }^{9}$, Abdur Rauf ${ }^{10}$, \\ Ghadeer M. Albadrani ${ }^{11}$, Amany A. Sayed ${ }^{12}$, Shaker A. Mousa ${ }^{13}$ and \\ Mohamed M. Abdel-Daim ${ }^{14,15}$
}

${ }^{1}$ Department of Pharmacy, Southeast University, Dhaka, Bangladesh, ${ }^{2}$ Pharmakon Neuroscience Research Network, Dhaka, Bangladesh, ${ }^{3}$ Department of Pharmacy, Brac University, Dhaka, Bangladesh, ${ }^{4}$ Teaching and Research Division, School of Chinese Medicine, Hong Kong Baptist University, Kowloon, Hong Kong, ${ }^{5}$ Department of Pharmacy, Noakhali Science and Technology University, Noakhali, Bangladesh, ${ }^{6}$ Institute of Health and Biomedical Innovation, Translational Research Institute, Brisbane, QLD, Australia, 'SChool of Clinical Sciences, Queensland University of Technology, Brisbane, QLD, Australia, ${ }^{8}$ Department of Pharmacy, BGC Trust University Bangladesh, Chittagong, Bangladesh, ${ }^{9}$ Department of Biology, Faculty of Sciences, University of Hafr Al Batin, Hafr Al Batin, Saudi Arabia, ${ }^{10}$ Department of Chemistry, University of Swabi, Khyber Pakhtunkhwa, Pakistan, ${ }^{11}$ Department of Biology, College of Science, Princess Nourah bint Abdulrahman University, Riyadh, Saudi Arabia, ${ }^{12}$ Zoology Department, Faculty of Science, Cairo University, Giza, Egypt, ${ }^{13}$ Pharmaceutical Research Institute, Albany College of Pharmacy and Health Sciences, Rensselaer, NY, United States, ${ }^{14}$ Department of Pharmaceutical Sciences, Pharmacy Program, Batterjee Medical College, Jeddah, Saudi Arabia, ${ }^{15}$ Pharmacology Department, Faculty of Veterinary Medicine, Suez Canal University, Ismailia, Egypt

Nuclear factor- $\mathrm{kB}(\mathrm{NF}-\mathrm{kB})$ is a transcription factor that regulates various genes that mediate various cellular activities, including propagation, differentiation, motility, and survival. Abnormal activation of NF-kB is a common incidence in several cancers. Glioblastoma multiforme (GBM) is the most aggressive brain cancer described by high cellular heterogeneity and almost unavoidable relapse following surgery and resistance to traditional therapy. In GBM, NF-кB is abnormally activated by various stimuli. Its function has been associated with different processes, including regulation of cancer cells with stem-like phenotypes, invasion of cancer cells, and radiotherapy resistance identification of mesenchymal cells. Even though multimodal therapeutic approaches such as surgery, radiation therapy, and chemotherapeutic drugs are used for treating GBM, however; the estimated mortality rate for GBM patients is around 1 year. Therefore, it is necessary to find out new therapeutic approaches for treating GBM. Many studies are focusing on therapeutics having less adverse effects owing to the failure of conventional chemotherapy and targeted agents. Several studies of compounds suggested the involvement of NF-kB signaling pathways in the growth and development of a tumor and GBM cell apoptosis. In this review, we highlight the involvement of NF- $\mathrm{kB}$ signaling in the molecular understanding of GBM and natural compounds targeting NF- $\mathrm{kB}$ signaling.

Keywords: NF-kB, glioblastoma, brain cancer, malignant, natural products, small molecules

\section{INTRODUCTION}

In the United States, around 17,000 malignant glioma incidents are identified yearly, and more than $80 \%$ of these are glioblastoma multiforme (GBM) (Dolecek et al., 2012). GBM is characterized by a remarkably heterogeneous and invasive kind of malignant brain cancer (Uddin et al., 2020a). It is considered the deadliest cancer, with a projected survival of about 14 months after confirming the 
diagnosis (Furnari et al., 2007). Resistance to conventional therapies and tumor relapse after surgery are mainly responsible for this poor prognosis. GBM is highly heterogeneous and shows various distinctive properties with the unique origin of cell types and different genetic lesions lead to various clinical behaviors (Stiles and Rowitch, 2008; Huse and Holland, 2010). Current developments in molecular technology, primarily next-generation sequencing and highdensity microarrays, have made it possible to classify GBM into subtypes according to the histological level and signatures of gene expression. Although many studies have tried to describe the various molecular subtypes of GBM (Phillips et al., 2006; Cooper et al., 2010; Verhaak et al., 2010; Huse et al., 2011), among them two subtypes, called proneural and mesenchymal (MES), tend to be stable and normally consistent amid the various proposed classifications. Furthermore, tumors identified as subtype MES demonstrate poor prognosis and have been associated with poor response to radiation, overexpression of $\mathrm{CD} 44$, and activation of nuclear factor- $\kappa \mathrm{B}(\mathrm{NF}-\kappa \mathrm{B})$ (Bhat et al., 2013). There is still an inadequate comprehending of the fundamental processes of development and the reappearance of gliomagenesis, despite the advancement in genetic analysis and GBM classification.

NF- $\kappa B$ belongs to a family of transcription factors that leads to the formation of various heterodimers or homodimers and attach to consensus DNA sequences at the promoter regions of target gene (Friedmann-Morvinski et al., 2016). NF- $\kappa B$ plays a pivotal role in the control of immunity, inflammation, and cell survival, as well as involves in various functions associated with cellular activities (Tilstra et al., 2011; Uddin et al., 2021). Activation of NF- $\kappa \mathrm{B}$ pathways could be triggered by different stimuli, such as DNA damage, cytokines, oncogenic stress, ultraviolet and ionizing radiation, pathogen-related molecular patterns, reactive oxygen species, and growth factors (Xia et al., 2014). Even though NF- $\kappa \mathrm{B}$ has been revealed to develop cancer by triggering and maintaining a pro-inflammatory microenvironment, however; constitutive activation of NF- $\kappa \mathrm{B}$ seems to induce tumor initiation and progression through several mechanisms, including apoptosis, proliferation of cells, metastasis of tumor, angiogenesis, and metabolism reprogramming (Xia et al., 2014). GBM has revealed that the constitutive NF- $\kappa \mathrm{B}$ activation induces development and survival. Moreover, sulfasalazine (an anti-inflammatory drug) has shown inhibitory action of NF- $\mathrm{BB}$ that triggers the apoptosis in glioma cells (Robe et al., 2004), and a decoy oligonucleotide strategy to prevent NF- $\kappa B$ that played a crucial role in the decline in the number of cells (Gill et al., 2002). Recently, the activation of NF$\kappa \mathrm{B}$ has been found to connect with the transformation of MES differentiation from proneural glioma stem cells, with related radioresistant properties.

The natural compounds-based treatment has paid attention in scientists in the last 2 decades as an efficient and possibly less toxic therapy for cancer (Kumar et al., 2020; Lin et al., 2020; Aziz et al., 2021; Huang et al., 2021). Long years ago, American Indians had used Podophyllum peltatum L. roots for the treatment of various skin cancers (Mann, 2002). Furthermore, the key anticancer ingredient podophyllotoxin and its semi-synthetic derivatives, such as etoposide, etopophos, and teniposide are used to treat many cancers (Schacter, 1996). From 1960 to 1985, two mega-scale anti-cancer drug-screening projects were launched by the National Cancer Institute (NCI) (Cragg et al., 1996). After screening, they have found a significant compound paclitaxel (Taxol), separated from the Taxus brevifolia Nutt. bark, which has subsequently been applied in the treatment of several solid tumors (Cragg et al., 1996). Furthermore, almost one-third of the therapeutic agents accepted for cancer by the Food and Drug Administration (FDA) were from natural compounds or their derivatives (Mann, 2002; Altmann and Gertsch, 2007). Plant flavonol quercetin inhibits NF- $\mathrm{B}$ transactivation in the U87 human glioma cell line at $20 \mu \mathrm{M}$ and demonstrates antiproliferative effects, necrosis/apoptosis activation, and cell cycle arrest in the U138MG human glioma cell line with lower cytotoxicity to normal cells (Braganhol et al., 2006; Braganhol et al., 2007; Park and Min, 2011). Another study has suggested that by regulating NF- $\kappa \mathrm{B}$ nuclear translocation and caspase-3 activation, a quercetin derivative causes cell death in glioma cells (Kiekow et al., 2016a). In this review, we focus on the role of NF$\kappa \mathrm{B}$ as a potential biomarker of GBM and highlight various natural compounds that affect the signaling pathway of NF- $\mathrm{BB}$ for treating GBM.

\section{STRUCTURAL AND FUNCTIONAL PROPERTIES OF NF-kB}

$\mathrm{NF}-\kappa \mathrm{B}$ is a protein complex that regulates DNA synthesis, survival, and cytokine production (Taniguchi and Karin, 2018). Indeed, all the proteins that belong to the NF- $\kappa B$ family possess the Rel homology domain in their N-terminal part. In terms of its structure, NF- $\kappa \mathrm{B}$ contains homodimers and heterodimers of the five members Rel family that are categorized into two groups. Furthermore, the first group of the protein complex is composed of c-Rel, RelA (p65), and RelB; on the other hand, the next group comprises NF- $\kappa \mathrm{B} 1$ (p105/p50) and NFkB2 (p100/p52) (Sun, 2011; Puliyappadamba et al., 2014) as shown in Figure 1. It has been reported that the first group (c-Rel, RelA, and RelB) proteins contain a transactivation domain in their C-terminus region. Alternatively, second group specifically NF- $\kappa \mathrm{B} 1$ and NF$\kappa \mathrm{B} 2$ proteins are generated as large precursors comprising p105 and p100 that play crucial roles in producing mature NF- $\kappa B$ subunits such as $\mathrm{p} 50$ and p52, successively. These NF- $\kappa \mathrm{B}$ subunits have no inherent capacity to mediate transcription, and when they interact as homodimers $\kappa \mathrm{B}$ components, they act as transcriptional repressors (Park and Hong, 2016).

It is known that kappa B (IkBs) inhibitors are a group of related enzymes with an N-terminal structural area, along with six or more ankyrin chains as well as a PEST domain adjacent to their $\mathrm{C}$ terminal domain. Even though the I $\mathrm{B}$ family is composed of various proteins including $\mathrm{Bcl}-3, \mathrm{I} \kappa \mathrm{B} \alpha, \mathrm{I} \kappa \mathrm{B} \beta$, and $\mathrm{I} \kappa \mathrm{B} \varepsilon$, among them IkBa has been extensively studied (Zhou et al., 2005). NF$\kappa \mathrm{B}$ is inactive in unstimulated cells due to its interaction with I $\mathrm{B} \alpha$ inhibitor, and the structure is usually found in the cytoplasm. I $\mathrm{KB}$ kinases $(\mathrm{IKK} \beta$ or IKKa) are induced and 


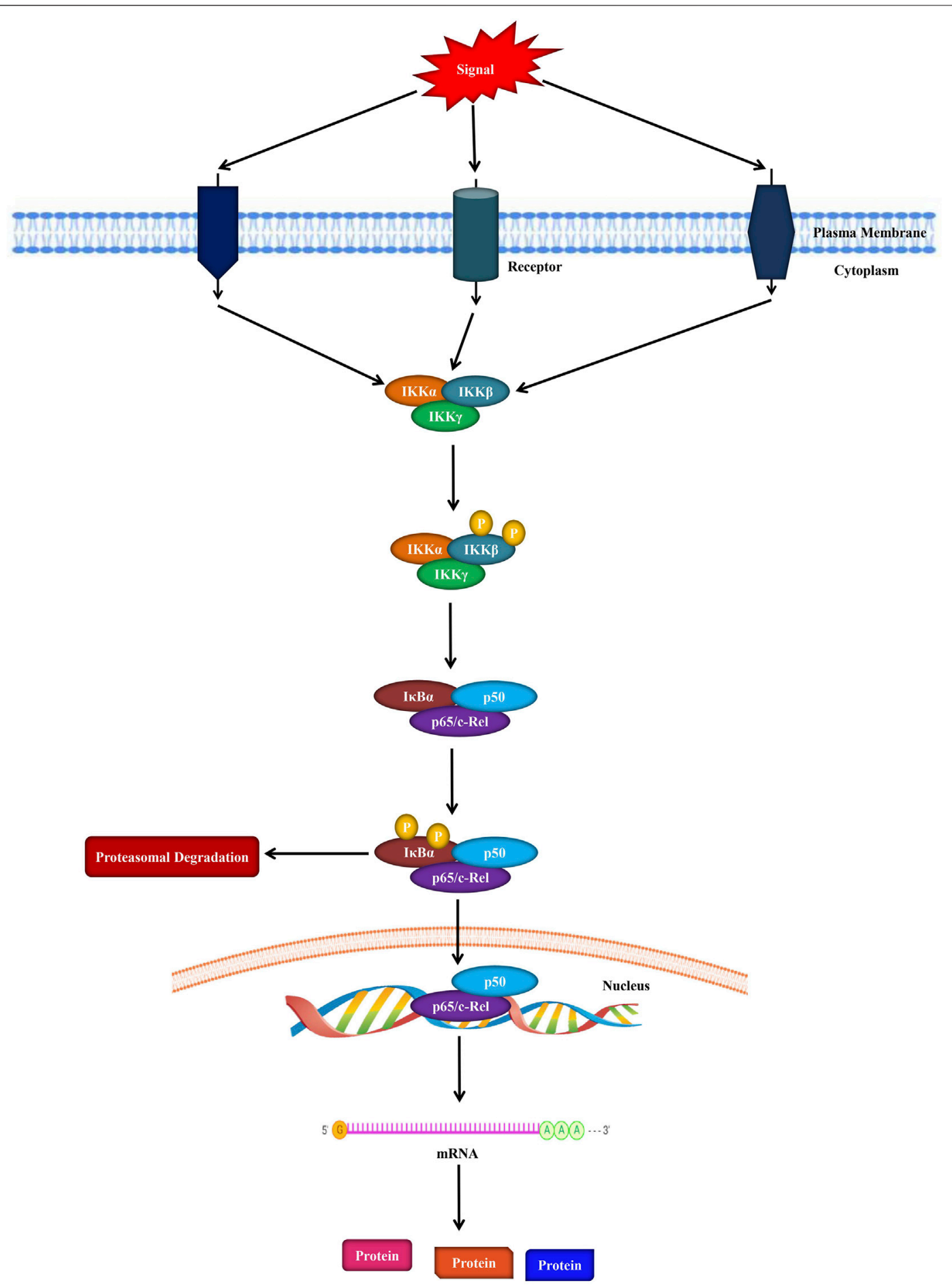

FIGURE 1 | Schematic representation of the NF-kB signaling in cells.

phosphorylate $\mathrm{I} \kappa \mathrm{B} a$ in response to various inducers including DNA damage, vascular endothelial growth factor (VEGF), epidermal growth factor (EGF), and cytokines [i.e., tumor necrosis factor (TNF)- $\alpha$ and TRAIL] that can further result in its degradation via a K48 ubiquitin-induced proteasomal mechanism (Park and Hong, 2016).
Several stimuli may induce the mammalian NF- $\kappa \mathrm{B}$ signaling pathways, such as growth factors, reactive oxygen species (ROS), oncogenic stress, DNA damage, pathogen-associated molecular patterns, ionizing and ultraviolet irradiation, various cytokines (TNF- $\alpha$ and IL-1 $\beta$ ), and stress (Gilmore, 2006; Sun, 2011). It has been revealed that NF- $\mathrm{BB}$ is associated with many processes 
including inflammation, chemoresistance, cell survival, angiogenesis, metastasis, tumor progression, invasion, cell cycle progression, immunity, metabolic reprogramming, and apoptosis (Dolcet et al., 2005; Grivennikov and Karin, 2010). Increased levels of inflammatory cytokines (for example, IL-1, IL15, IL-11, IL-6, and IL-8), C-C motif chemokine ligand (CCL)-2, and genes associated with pathological processes such as cyclooxygenase (COX)-2, cell adhesion (CD44), cell cycle modulators (Cyclin D1), and proteolysis (TFPI2, PLAU) are all known targets of the NF- $\kappa \mathrm{B}$ signaling pathway (Richmond and Yang, 2016). Along with the nuclear translocation, several regulatory mechanisms, such as nuclear export processes, protein-protein interactions located in certain gene regulatory regions, and post-translatory changes of specific subunits of NF$\kappa \mathrm{B}$, are controlled by the NF- $\kappa \mathrm{B}$ signaling pathway. As a result, various cellular responses to NF- $\kappa \mathrm{B}$ are frequently caused by specific and complex pathways that vary in their upstream stimuli and/or downstream targets (Gilmore, 2006).

\section{NF-kB IN GLIOBLASTOMA}

In case of GBM and other cancers, the NF- $\kappa \mathrm{B}$ signaling pathway is found to be activated and is associated with a higher grade of astrocytic tumors. Characteristics of the mesenchymal subtype of GBM include increased concentrations of NF- $\kappa B$ signaling pathway constituents such as TNF receptor superfamily member 1A [(TNFRSF1A), v-rel reticuloendotheliosis viral oncogene homolog B (RELB), and TNFR1-associated death domain protein (TRADD)], elevated resistance towards chemotherapy and a lesser prognosis as compared to individuals with other GBM types (Verhaak et al., 2010). It has been established that an NF- $\mathrm{BB} / \mathrm{TNF}-$ (tumor necrosis factor)-mediated mechanism can differentiate proneural individual-derived neurospheres to a mesenchymal phenotype, which has been linked to poor prognosis and radioresistance (Bhat et al., 2013). These findings collectively suggest the significance of the NF- $\kappa \mathrm{B}$ signaling during the development and advancement of glioma. Applying gliomas as an experimental model for network analyses, it was observed that NF- $\kappa \mathrm{B}$ signaling pathway dysregulation was 1 of 4 signaling mechanisms whose perturbation was slightly satisfactory to maintain the phenotype of malignant glioma (Karlebach and Shamir, 2010).

Nonetheless, the specific mechanism(s) of in vivo NF- $\kappa \mathrm{B}$ activation in case of GBM is still unidentified. However, various proteins and signaling mechanisms are dysregulated in the case of GBM which might result in NF- $\kappa B$ activation. TNF- $\alpha$ is a very strong NF- $\kappa B$ activator (Grivennikov and Karin, 2011). TNF- $\alpha$ is a pro-inflammatory chemical that is released by astrocytes, microglia, and certain neurons in the CNS. Indeed, TNF- $\alpha$ exhibits its effect via two receptors including TNF receptor 1 (TNFR1) and TNF receptor 2 (TNFR2) (Grivennikov and Karin, 2011). Usually, TNFR1 is expressed in most type of the cells, whereas TNFR2 is expressed in oligodendrocytes and immune cells, including microglia. Furthermore, TNFR1 expression was found to be higher in
GBM and GBM-linked endothelial cells than in normal brain tissues or low-grade gliomas (Hayashi et al., 2001; Kargiotis et al., 2006; Huang et al., 2012a).

Many signaling pathways or growth factors that are dysregulated in case of gliomas may result in the activation of NF- $\kappa$ B (Nogueira et al., 2011a). Particularly, NF- $\kappa B$ is activated via epidermal growth factor (EGF), and/or its receptor, (EGFR). It has been observed that EGFR is often mutated and constitutively activated (Bonavia et al., 2012; Yang et al., 2012; Puliyappadamba et al., 2013). Furthermore, oncogenic EGFR is associated with NF- $\kappa \mathrm{B}$ activation by means of mechanistic target of rapamycin complex 2, and this signaling pathway mediates chemoresistance (Tanaka et al., 2011). Phosphatase and tensin homolog (PTEN) is a suppressor of tumor and a negative regulator of the Akt signaling pathway (Atkinson et al., 2010). It has been found that numerous gliomas exhibited loss of PTEN function (Atkinson et al., 2010). Akt is constitutively activated in case of PTEN absence, which can further result in NF- $\kappa \mathrm{B}$ activation. Increased insulin-like growth factor binding protein-2 (IGFBP-2) concentrations and the signaling mechanism were found to be connected with an increased level of NF- $\kappa B$ signaling pathway (Holmes et al., 2012). In case of GBM, IGFBP2 binds specifically with $\beta 1$ integrin in order to activate an integrin-linked kinase (ILK)/NF- $\mathrm{BB}$ cascade that further mediates the growth of glioma.

Various findings have suggested that abnormal expression of regulators can lead to increased activation of NF- $\kappa B$. In GBM, the inhibitor of growth family member 4 (ING4, a negative NF- $\kappa B$ regulator) is expressed at very low concentrations or is mutated. In addition, deficiency of the ING4 effect activates NF- $\kappa B$ to remain active (Nozell et al., 2008). In contrast, peptidyl-prolyl isomerase (Pin1, a positive NF- $\kappa \mathrm{B}$ regulator) was found to be overexpressed in case of GBM and plays role in constitutive activation of NF-kB (Atkinson et al., 2009). Plant homeodomain finger protein 20 (PHF20, an effector protein that binds with methylated p65) is a newly identified NF- $\kappa B$ regulator in GBM, which averts phosphatase $\mathrm{PP} 2 \mathrm{~A}$ recruitment, therefore it prolongs the presence of an active species of NF- $\kappa B$ in case of GBM (Zhang et al., 2013). It has been reported that the NFKBIA gene (that encodes I $\mathrm{KB} \alpha$ ) shows mono-allelic deletions in some GBM types, which is often lost in a subtype-specific manner in $\mathrm{GBM}$, and this associates with increased levels of NF- $\mathrm{BB}$ as well as inferior prognosis of patients (Bredel et al., 2011). In a study, Pantane et al. (2013) confirmed that deletions of NFKBIA were elevated when tumors were spread as neurospheres in comparison with the deletions of parent tumor, which is further indicating that NFKBIA loss can mediate tumorpropagating activities and the formation of neurosphere. Collectively, these findings suggest the significance of the NF$\mathrm{\kappa B}$ signaling pathway in the stem cells of glioblastoma (Hjelmeland et al., 2010; Nogueira et al., 2011b).

Although many microRNAs (miRs) were found to be dysregulated and associated with the clinical-pathological characteristics of gliomas, but few of these were related to the NF- $\kappa B$ signaling pathway (Hummel et al., 2011). Oncogenic miRs (including miR-30e, miR-182, and miR-21) were linked with the NF- $\kappa B$ signaling pathway in GBM. Furthermore, miR-21 levels 
were much higher than in non-cancerous brain tissue in GBM, and were inversely related to patient prognosis. miR-21 levels were markedly increased as compared to non-cancerous brain tissue in GBM and inversely associated with the prognosis of patients (Chan et al., 2005; Ciafrè et al., 2005; Chen et al., 2008; Papagiannakopoulos et al., 2008; Lakomy et al., 2011). In GBM, overexpressed miR-21 induces $\mathrm{NF}-\kappa \mathrm{B}$ signaling pathway via targeting the leucine-rich repeat flightless-1-interacting protein 1 (LRRFIP1, a DNA-binding protein that inhibits the NF- $\kappa B$ signaling pathway) (Li et al., 2009). In terms of miR-182, around $98 \%$ of gliomas showed increased levels of miR-182. Moreover, the number of miR-182 copy was increased by 2-3 folds in approximately $35.6 \%$ glioma cases (Song et al., 2012). TGF- $\beta$ increases miR-182 levels in GBM, which further mediates NF- $\kappa B$ signaling pathway via targeting various negative regulators of NF$\kappa \mathrm{B}$, such as $\mathrm{TNF}-\alpha$-induced protein 3 -interacting protein 1 (TNIP1), optineurin (OPTN), ubiquitin specific peptidase 15 (USP15), and cylindromatosis (CYLD). As compared to normal brain, the miR-30e level was increased in GBM and sustained NF- $\kappa \mathrm{B}$ signaling pathway through the targeting of IкBa (Jiang et al., 2012).

Only a few tumor suppressive miRs have been related to the NF- $\kappa B$ signaling pathway in GBM until now. Some studies have been reported that miR-31 is mainly absent or downregulated in GBM (Hua et al., 2012; Wang et al., 2014) and its existence is found in both the classical and mesenchymal subtypes of GBM. Decreased levels of miR-31 are also a part of $10 \mathrm{miR}$ expression feature that predicts patient survival independently (Srinivasan et al., 2011). It was revealed that miR-31 inhibits the NF- $\kappa B$ signaling pathway by targeting TRADD (a protein that plays a role as an upstream activator). In addition, both increased TRADD levels and miR-31 loss have been identified in case of mesenchymal subtype of GBM. Indeed, the aforesaid miRs offer an interesting miRs sampling which play role in $\mathrm{NF}-\kappa \mathrm{B}$ regulation, however the list of such miRs is quite lengthy and increasing (Song et al., 2013; Xia et al., 2013; Yang et al., 2014).

\section{PRECLINICAL STUDIES OF NF- $\kappa B$ SIGNALING IN GLIOBLASTOMA}

Still, it is challenging to target NF- $\kappa \mathrm{B}$ for GBM. Furthermore, there is also a deficiency of specific and effective compounds. Nonetheless, bortezomib is a promising proteasome inhibitor that hinders the breakdown of I $\mathrm{BB} \alpha$ as well as other proteins (Yin et al., 2005; Phuphanich et al., 2010). In addition, phase I clinical trials were also started for evaluating the maximum tolerated dose and side effects of bortezomib (Phuphanich et al., 2010). Even though that study did not provide extensive data regarding the efficacy of bortezomib in GBM, but there were some findings to suggest its clinical efficacy (Phuphanich et al., 2010). However, bortezomib is not yet considered a single-agent therapy for GBM treatment. In recent times, BAY-11 (an inhibitor of IKK) has been identified as the eminent NF- $\kappa B$ signaling pathway inhibitor. This inhibitor also mediated in vivo and in vitro senescence of GBM cells, ameliorated sensitivity towards photodynamic (5-ALA) therapy, and reversed chemoresistance (Coupienne et al., 2011; Nogueira et al., 2011b; Shukla et al., 2013). Interestingly, dehydroxymethylepoxyquinomicin (DHMEQ) has been identified as a unique small molecule NF- $\mathrm{BB}$ inhibitor (Fukushima et al., 2012). It has been confirmed by preclinical studies that DHMEQ inhibited activation of $\mathrm{NF}-\kappa \mathrm{B}$ and its nuclear translocation, resulting in decreased tumor growth in vivo as well as reduced proliferation in GBM cells in vitro. Furthermore, treatment with DHMEQ was found to be synergized with radiation and temozolomide, which is suggesting its significant therapeutic potential (Brassesco et al., 2013). It has also been confirmed that withaferin A (an inhibitor of IKK $\beta$ ) significantly inhibits $\mathrm{NF}-\mathrm{\kappa B}$ signaling and GBM growth in vivo (McFarland et al., 2013). Even though withaferin A is presently being studied in a schizophrenia clinical trial (ClinicalTrials.gov Withan, 1793) and its extract for endurance exercise performance (ClinicalTrials.gov The Ef, 2021) but it is not under consideration for GBM treatment.

\section{NATURAL PRODUCTS TARGETING NF-кB SIGNALING IN GLIOBLASTOMA}

\section{Resveratrol}

Resveratrol (a stilbenoid, naturally occurring polyphenolic compound, Figure 2) exhibited anti-invasion, immunomodulation, anti-inflammatory, and antitumor properties in several cancer cells (El-Readi et al., 2019; Jeandet et al., 2021). Numerous experiments have confirmed that resveratrol significantly supresses the NF- $\mathrm{KB}$ signaling via suppressing the activities of I $\kappa \mathrm{B}$ kinase and NF- $\mathrm{KB}$, which has provided a novel approach for cancer treatment (Ren et al., 2013; Vervandier-Fasseur and Latruffe, 2019). In a study, Jiao et al. (2015) confirmed that resveratrol suppressed PI3K/Akt/NF-kB signaling cascade that led to the inhibition of matrix metalloproteinase (MMP)-2 expression, which further resulted in suppression of attack in GBM-initiating cells. Furthermore, it was confirmed that there is a connection between the NF- $\kappa B$ effect and invasiveness of GBM (which takes place because of the processing of fibronectin via MMPs), which allows the direct integration of MMPs into the surrounding tumor cells (Westhoff et al., 2013). In addition, in GBM cells (T98G), resveratrol reversed the temozolomide resistance via O-6-methylguanineDNA methyltransferase (MGMT) downregulation via the NFкB-dependent pathway (Huang et al., 2012b). Many studies suggested that the NF- $\mathrm{KB}$ activation in multiple tumor cells (primarily associated with drug resistance), which was found to be facilitated via numerous chemotherapy medicines and radiation because of its action in MGMT transcription (Li and Sethi, 2010). Interestingly, NF-kB-p65 (an NF-kB subunit) resulted in increased MGMT expression, whereas an inhibitor of NF- $\kappa B$ abolished the increased expression of MGMT. (Hegi et al., 2005; Arepalli et al., 2015). Therefore, targeting MGMT, IкB kinase, and NF- $\kappa$ B may be beneficial in the resveratrol's antiGBM potential. 
<smiles>Oc1ccc(/C=C/c2cc(O)cc(O)c2)cc1</smiles>

Resveratrol<smiles>O=c1cc(-c2ccc(O)cc2)oc2cc(O)cc(O)c12</smiles>

Apigenin<smiles>O=c1cc(-c2ccccc2)oc2cc(O)c(O)c(O)c12</smiles>

Baicalein<smiles>CS(=O)CCCCN=C=S</smiles>

Sulforaphane

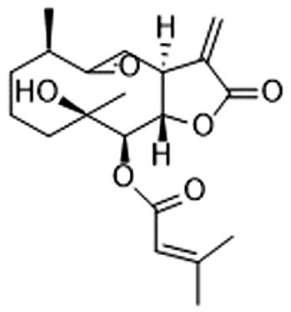

Nepalolide A<smiles>O=c1c(O)c(-c2ccc(O)c(O)c2)oc2cc(O)cc(O)c12</smiles>

Quercetin<smiles>[R]N=C=S</smiles>

Isothiocyanates<smiles>C=C1C(=O)O[C@@H]2C[C@@]3(C)CCC[C@H](C)C3=C[C@H]12</smiles>

Alantolactone<smiles>C/C1=C\CC[C@H]2C(=O)C(=O)O[C@@H]2C2CC[C@@]1(C)O2</smiles>

Parthenolide<smiles>COc1cc(/C=C/C(=O)CC(=O)/C=C/c2ccc(O)c(OC)c2)ccc1O</smiles>

Curcumin

FIGURE 2 | Chemical structures of the discussed molecules.

\section{Quercetin}

Quercetin (a plant flavonoid, Figure 2) can induce cell death of brain, liver, and breast cancer cells (Anand David et al., 2016). Furthermore, this phenolic compound shows antioxidant, neuroprotective, anti-inflammatory, anticarcinogenic, and antihypertensive properties (Reyes-Farias and Carrasco-Pozo, 2019; Zaplatic et al., 2019). It has been revealed that quercetin has the capacity to regulate several protein kinases, particularly the PI3K pathway (Liu et al., 2017a). In a study, Liu et al. (2017b) studied the activity of quercetin $(10 \mu \mathrm{g} / \mathrm{ml})$ on cell invasion and migration. These researchers observed that a low dose of quercetin suppressed in vitro angiogenesis and glioblastoma cell invasion. In addition to this, they reported that quercetin $(10 \mu \mathrm{g} / \mathrm{ml})$ suppressed cell migration and human umbilical vein endothelial cell tube formation mediated via the U251 cell culture-derived conditioned medium. This suppressive action of quercetin on angiogenesis and migration might be induced by the downregulation of protein concentrations of MMP-2, MMP-9, and vascular endothelial growth factor (Liu et al., 2017b). In a study, Kiekow et al. (2016b) revealed that quercetin stimulates apoptosis in GBM cells via regulating activation of caspase-3 and nuclear translocation of NF- $\mathrm{BB}$, which is further indicating the potential of quercetin as a novel anti-GBM therapy. Phospholipase D (PLD) 
overexpression induced MMP-2 expression. Therefore, GBM cell invasion by protein kinase $\mathrm{A}(\mathrm{PKA}) / \mathrm{NF}-\kappa \mathrm{B}$ and protein kinase C-induced signaling mechanisms (Park et al., 2009; Tang et al., 2017). Furthermore, it was shown that quercetin suppressed the NF- $\kappa B$-mediated expression of PLD-1 by the mitigation of NF- $\kappa B$ transactivation (Park and Min, 2011).

\section{Apigenin}

Apigenin is a natural flavone, (Figure 2) which is mostly found in tea leaves and fruits exhibits several biological properties including anticancer (prostate, liver, breast, and lung cancers), anti-inflammatory, antiviral, cytotoxic, antioxidant, and immunoregulatory properties (Erdogan et al., 2016; Yan et al., 2017). Apigenin's immunoregulatory property is induced via the suppression of $\mathrm{PI} 3 \mathrm{~K} / \mathrm{Akt} / \mathrm{NF}-\mathrm{\kappa B}$ signaling cascade (control of IKK and $I \kappa B a$ ) signaling pathways in various cancers (Chang et al., 2015; Erdogan et al., 2016; Qin et al., 2016), which can further result in a decreased level of metastasis and invasion. Chen et al. (2016) confirmed that apigenin in a dose-dependent manner markedly reduced cell viability and triggered apoptotic cell death of U87 cells. In U87 cells, it was confirmed that apigenin markedly elevated the levels of microRNAs (miR)-16, inhibited the NF- $\mathrm{BB} / \mathrm{MMP}-9$ pathway, and also inhibited the expression of BCL2 protein. Interestingly, anti-miR-16 plasmidmediated miR-16 downregulation was found to reverse the activity of apigenin on NF- $\mathrm{B} / \mathrm{MMP}-9$ signaling pathway, expression of BCL2 protein, and cell viability. Collectively, findings of the study indicated that apigenin suppresses glioma cell growth via inducing miR-16 and inhibiting NF- $\kappa B / M M P-9$ and BCL2 (Chen et al., 2016).

\section{Isothiocyanates}

Isothiocyanates (Figure 2) are natural compounds derived from the glucosinolate precursors of cruciferous vegetables, which exert anticancer, anti-invasion, and anti-inflammatory actions via inhibiting breast cancer, pancreatic cancer, and myeloma (Prawan et al., 2009; Brunelli et al., 2010). Many studies have reported that the anti-inflammatory effects of isothiocyanates in multiple cancer cells (Subedi et al., 2017; Mitsiogianni et al., 2019). The consequences have indicated that the antiinflammatory properties of isothiocyanates may be mediated by the inhibition of $c$-Jun N-terminal kinase (JNK)/NF- $\kappa \mathrm{B} /$ TNF- $\alpha$ signaling pathways (Subedi et al., 2017). In a study, Guo et al. (2019) assessed the possible synergistic action of phenethyl isothiocyanate in combination with temozolomide and theorized that phenethyl isothiocyanate might facilitate the anticancer role of temozolomide partly via NF- $\mathrm{BB}-$ dependent signaling pathway reducing MGMT expression. Furthermore, treatment with phenethyl isothiocyanate elevated the sensitivity of temozolomide resistant U373, U87, and T98 cells via suppressing the MGMT expression through the NF- $\kappa \mathrm{B}$ signaling cascade (Guo et al., 2019). In order to examine the inhibitory effects of isothiocyanates on cancer invasion and migration, Lee et al. (2015) looked at isothiocyanate-regulated MMP-9 activation in C6 glioma cells. MMP-9 is a crucial enzyme in cancer metastasis that destroys the extracellular matrix. They revealed that isothiocyanates suppressed MMP-9 transcription levels via inhibiting NF- $\kappa \mathrm{B}$ and activator protein-1 (AP-1), which further preventing C6 GBM cell motility and invasion (Lee et al., 2015).

\section{Sulforaphane}

Sulforaphane (a natural isothiocyanate group of organosulfur compounds, Figure 2) is derived from broccoli sprouts (Uddin et al., 2020b). Sulforaphane shows cancer-protective effects via detoxifying and ameliorating antioxidant capacity (Clarke et al., 2008; Cheung and Kong, 2010). In human cancer cells, sulforaphane-mediated inhibition of NF- $\kappa$ B and NF- $\kappa$ Bregulated gene expression takes place via IкBa and IKK signaling pathways (Xu et al., 2005). Sulforaphane altered caspase-9/-12 cleavage, cytochrome C release, calpain effect, DNA fragmentation, intracellular $\mathrm{Ca}^{2+}$ level, morphological characteristics, Bcl-2-associated X-protein (Bax)/B-cell lymphoma $2(\mathrm{Bcl}-2)$ ratio, and levels of $\mathrm{I} \kappa \mathrm{Ba}$ protein in $\mathrm{U}-87$ MG and T98G GBM cells (Lenzi et al., 2014). In GBM cells, sulforaphane suppressed the inhibitor of apoptosis proteins and $\mathrm{I} \kappa \mathrm{Ba}$ up-regulation, resulting in downregulation of $\mathrm{NF}-\kappa \mathrm{B}$ expression (Huang et al., 2012c). Lan et al. (2016) showed that sulforaphane might markedly inhibit proliferation of temozolomide-resistant GBM cells. Sulforaphane also suppressed the function of NF- $\kappa \mathrm{B}$ pathway and then decreased the expression of MGMT in order to reverse the chemo-resistance to temozolomide in U373-R, U87-R, and T98G cell lines. Moreover, sequential combination with temozolomide synergistically elevated apoptosis induction and suppressed survival capability in temozolomide-resistant GBM cells. It was also suggested that sulforaphane might significantly increase cell death and inhibit cell growth in a chemo-resistant xenograft nude-mouse model (Lan et al., 2016). In a different study, Li et al. (2014) observed that sulforaphane suppresses invasion via inducing activation of ERK1/2 signaling pathway in human glioblastoma U373MG and U87MG cells. BijangiVishehsaraeiv et al. (2017) confirmed that sulforaphane markedly suppresses GBM cell survivals and triggers apoptosis in GBM cells linked with the elevated activity of caspase- 3 and -7 . In addition, sulforaphane did not influence normal human mesenchymal stromal cells and exerted modest action on the nontumor brain cells.

\section{Alantolactone}

Alantolactone, a sesquiterpene lactone extracted from Inula helenium L. (Figure 2), has many pharmacological properties, including anticancer, antibacterial, antifungal, and antiinflammatory properties (Chun et al., 2012). Alantolactone's antitumor activities were observed in chronic myelogenous leukemia, brain tumors, colorectal cancer, lung cancer, and liver cancer (Khan et al., 2012; Rasul et al., 2013; Wei et al., 2013). In GBM cells, alantolactone caused cell death through glutathione depletion, mitochondrial dysfunction, and ROS production (Khan et al., 2012). Furthermore, alantolactoneinduced other mechanisms triggered involve suppression of inducible nitric oxide synthase (iNOS) and COX-2 expression and downregulation of $\mathrm{NF}-\kappa \mathrm{B}$ and $\mathrm{AP}-1$ through myeloid differentiation primary response 88 (MyD88) signaling (Chun 
et al., 2012). In a study, Wang et al. (2017) revealed that alantolactone's antitumor activity against GBM. This study found that the alantolactone dramatically inhibited the growth of GBM. Alantolactone inhibited the kinase activity of IKK $\beta$ by targeting the ATP-binding site and then attenuated the binding of $\mathrm{NF}-\kappa \mathrm{B}$ to the COX-2 promoter area, resulting in a considerable reduction in COX-2 expression. Alantolactone also triggered apoptosis by activating the caspase/cytochrome $\mathrm{c}$ signaling pathway. Furthermore, alantolactone can penetrate the bloodbrain barrier (BBB). Thus anti-tumor effects of alantolactone is facilitated by blocking the activity of IKK $\beta$ kinase as well as affecting NF- $\kappa \mathrm{B} / \mathrm{COX}$-2-induced signaling mechanisms in GBM (Wang et al., 2017). Therefore, due to its dual inhibitory effects on $\mathrm{NF}-\kappa \mathrm{B}$ and IKK $\beta$ expression, alantolactone may be considered a promising natural compound against GBM.

\section{Baicalein}

Baicalein (a bioactive flavone, Figure 2) is derived initially from Scutellaria baicalensis Georgi and Scutellaria lateriflora L. (Varsha et al., 2017). This flavone has traditionally been utilized because of its anticancer activities (Liu et al., 2016; Zhao et al., 2016). In multiple cancer cell lines, aicalein inhibited the nuclear translocation of NF- $\mathrm{BB}$ and exerted antiinflammatory activities (Seo et al., 2011; Yu et al., 2018a). Moreover, baicalein inhibited the C33A growth and accelerated cellular apoptosis by blocking NF- $\kappa \mathrm{B}$ spathway (Yu et al., 2018a). After treatment with baicalein, NF- $\kappa B-p 65$ activity and expression were markedly suppressed in U251 GBM cells (Jiang et al., 2016). The use of an NF-kB-p65 inhibitor (EVP4593) combined with baicalein resulted in a synergistic reduction of $\mathrm{Bcl}-$ 2 expression, followed by an increase in Bax and cleaved-caspase3 expression, as well as the inhibition of U251 cell survival (Jiang et al., 2016). All of these finding indicating that baicalein might be therapeutically used as a natural compound against GBM.

\section{Parthenolide}

Parthenolide (a naturally occurring sesquiterpene lactone, Figure 2) is extracted from Tanacetum parthenium L. (Chaturvedi, 2019). This naturally occurring compound inhibits NF- $\kappa \mathrm{B}$ via suppressing the activity of I $\mathrm{B}$ kinase as well as altering the p65 subunit (Kwok et al., 2001). Furthermore, parthenolide has traditionally been used to treat rheumatoid arthritis and migraine because of its antiinflammatory properties and low toxicity (Heptinstall, 1988). In numerous studies, the effects of parthenolide on animal malignancies have been widely explored (Gilmore, 2006; Haffner et al., 2006). It was revealed that parthenolide inhibited proliferation, angiogenesis, and invasion of GBM cells (U87MG and U373). In a study, Yu et al. (2018b) revealed that the suppression of NF- $\kappa \mathrm{B}$ resulted in anti-GBM effect and suppressed temozolomide-mediated chemoresistance via downregulation of MGMT gene expression. Furthermore, it has been confirmed by Nakabayashi and Shimizu (2012) that parthenolide inhibits angiogenesis and decreases phosphorylation of Akt and activated mitochondrial signaling pathway, which is suggesting that the antitumor effect of parthenolide might be induced via stimulation of apoptosis, suppression of Akt signaling pathway, and NF- $\kappa \mathrm{B}$ suppression. In glioblastoma xenografts, parthenolide reduced neovascularity and tumor development (Nakabayashi and Shimizu, 2012). However, it has been observed that treatment with parthenolide causes rapid cell death via caspase-3/-7 without influencing the regulation of NF- $\kappa \mathrm{B}$ in GBM cells (Anderson and Bejcek, 2008).

\section{Nepalolide A}

Nepalolide A (a naturally occurring germacranolide sesquiterpene lactone, Figure 2) is derived from Carpesium nepalense Less. (Wang et al., 1999). In C6 glioma cells and primary astrocytes, the effects of nepalolide $\mathrm{A}$ on the production of iNOS generated by LPS/IFN- $\gamma$ or TNF- $\alpha /$ IL- $1 \beta /$ IFN- $\gamma$ were studied by Wang et al. (1999). This study reported that nepalolide A inhibited signaling pathways induced via cytokine and lipopolysaccharide and also suppressed the phosphorylation of IкB protein (Wang et al., 1999). Thus, suppression of NF- $\kappa \mathrm{B}$ activation via nepalolide $\mathrm{A}$ was facilitated via blocking I $\mathrm{KB}$ degradation, which can further result in suppression of iNOS expression (Wang et al., 1999).

\section{Curcumin}

Curcumin (a polyphenol, Figure 2) is the major bioactive compound of Curcuma longa L. that exerts anti-inflammatory and antioxidant properties by decreasing the activity of AP-1 and NF- $\kappa B$ (Saberi-Karimian et al., 2019). Its potential to treat various high-risk cancers has also been assessed in phase I clinical trials (Cheng et al., 2001). Furthermore, curcumin might exert numerous beneficial effects in GBM cells, such as suppression of angiogenesis, cell development, and invasion (Ambegaokar et al., 2003; Gao et al., 2005; Kim et al., 2005). Its activities on GBM development were also studied in the rat (C6) and human (T98G, T67, and U87MG) GBM cell lines. Furthermore, curcumin decreased the survival of cells in a p53-and caspaseindependent manner, an activity which is linked with the suppression of $\mathrm{NF}-\kappa \mathrm{B}$ and $\mathrm{AP}-1$ signaling pathways by the deterrence of constitutive Akt and JNK activation (Dhandapani et al., 2007). Curcumin also induced the antitumor effect of nimustine (a nitrosourea with antineoplastic activity) against GBM via inhibiting the NF- $\kappa \mathrm{B} /$ COX-2 and PI3K/Akt signaling cascades (Zhao et al., 2017a). In a study, Fratantonio et al. (2019) reported that curcumin triggered the anti-GBM effect of paclitaxel by suppressing NF- $\kappa B$ activation in rat C6 cells. In U87 cells, demethoxycurcumin (a curcuminoid) exerted anti-proliferative effects via inhibition of the Akt/NF- $\kappa \mathrm{B}$ signaling cascade (Kumar et al., 2018).

In a study, Wu et al. (2015) determined whether the cytotoxic effects of curcumin in glioblastoma cells is facilitated via miR146a upregulation. Roles of curcumin and temozolomide (alone or in combination) on apoptosis and cell proliferation were assessed in human U-87 MG glioblastoma cells. Curcumin treatment resulted in miR-146a upregulation in U-87 MG cells. As compared to single treatment, combined treatment curcumin and temozolomide markedly $(p<0.05)$ stimulated apoptotic death and suppressed proliferation of U-87 MG cells. Depletion of miR-146a blocked the curcumin-induced 
enhancement of temozolomide-mediated apoptosis (Wu et al., 2015). Overexpression of miR-146a inhibited activation of NF- $\kappa B$ and increased apoptosis in temozolomide-treated cells. Furthermore, pharmacological suppression of NF- $\mathrm{B}$ signaling pathway markedly elevated temozolomide-mediated apoptosis (Wu et al., 2015).

\section{NATURAL MOLECULES AND BLOOD-BRAIN BARRIER PERMEABILITY}

The brain is incredibly equipped with a significant protective element known as the BBB. BBB plays a role in preventing harmful substances from entering the brain. Because of this property of $\mathrm{BBB}$, most of the new drugs cannot enter into and treat the brain tumor. Furthermore, $\mathrm{BBB}$ is one of the major challenges that researchers need to overcome to develop novel and effective treatments for individuals with malignant brain tumors (Noch et al., 2018). Indeed, BBB regulates the entry of various molecules into the brain via transcellular or paracellular signaling pathways. It has been reported that BBB also contains many tight junctions between endothelial cells, ATP-dependent multidrug resistance pathway proteins called P-glycoprotein (P-gp), enzymes, and receptors (Chow and Gu, 2015). Components of the $\mathrm{BBB}$ microenvironment include extracellular matrix, basement membrane, fibroblasts, neurons, pericytes, microglia, and astrocytes (Obermeier et al., 2013), which also affect BBB activities (Lécuyer et al., 2016; Zhao et al., 2017b). It has been identified that blood-brain tumorbarrier (BBTB) arises from tumor capillaries providing oxygen and nutrients to the tumor (Tellingen et al., 2015). On the other hand, the glioma BBTB microenvironment contains infiltrating macrophages, tumor-linked microglia, extracellular matrix, tumor cells, and various other types of cells. In rat GBM models, tumor growth was suppressed by targeting the glioma microenvironment (Jacobs et al., 2012). Targeted therapy has gained a lot of attention over time, but this therapy did not raise the overall survival of individuals with GBM, partly owing to the poor drug penetration across the BBB. Thus, there is a growing interest regarding the molecules that can modulate $\mathrm{BBB}$ permeability to ameliorate the bioavailability of therapeutic agents into tumors. Furthermore, nanotechnology is essential to mask the physicochemical properties of therapeutic agents to prolong half-life across the BBB (Gerstner and Fine, 2007).

In the case of brain cancer treatment, targeted delivery of resveratrol into the brain tumor tissue might overcome various issues, including chemical instability, poor water solubility, and low bioavailability of resveratrol. Multiple types of polymeric nanoparticles and liposomes have already been developed to enhance GBM treatment. In a study, Vijayakumar et al. (2016) showed that the antiglioma cytotoxicity, passive brain targeting, and biological half-life of resveratrol were markedly improved via utilizing D- $\alpha$-tocopheryl polyethylene glycol-1000 succinatecoated liposomes. In another study, Guo et al. (2013) altered the surface of resveratrol-loaded polyethylene glycol-polylactic acid nanoparticles with transferrin moieties (Tf-NP), which further resulted in increased cytotoxicity, elevated level of intracellular uptake, and apoptosis of human U-87 MG GBM cell lines and C6 rat glioma cells in vitro, as compared to nanoparticles without transferrin and free resveratrol. As transferrin receptors are only expressed in brain capillaries (Johnsen et al., 2017), the buildup of Tf-NP-resveratrol in tumor tissues prolonged survival and reduced tumor volume in rat models containing C6 orthotopic glioma. In a study, Wei et al. (2015) observed that treatment with resveratrol protected BBB integrity via regulating activities and expressions of TIMP-1 and MMP-9 in brains of rat models that were reperfused after ischemic injury.

Quercetin was found to cross the $\mathrm{BBB}$ and decrease the advancement of degenerative diseases ( $\mathrm{Li}$ et al., 2015). It has been suggested that $\alpha$-tocopherol can mediate the transport of quercetin through the BBB. In the brain, the combination of quercetin and rutin mediated the buildup of quercetin and/or its conjugated derivatives (Ferri et al., 2015). Quercetin was found to improve $\mathrm{BBB}$ dysfunction, reduce $\mathrm{BBB}$ leakage, and decrease brain edema (Aziz et al., 2021). Quercetin may decrease the expressions of axin, GSK-3 $\beta$, and MMP-9, and elevate the expression of $\beta$-catenin, claudin-5, and ZO-1. Interestingly, all these protective activities of quercetin might be reversed via DKK-1 (Aziz et al., 2021). Adhesion molecules, membrane proteins, or invasion-linked proteins may play roles in tumor invasion and migration. In human glioblastoma cells, sulforaphane-cysteine suppressed the invasion and migration by increasing the fusion of mitophagosome to the lysosome (Zhou et al., 2020). Collectively, these findings might help in developing low-toxicity and high-efficiency anticancer drugs to suppress invasion and migration in GBM. Wang et al. (2013) confirmed that curcumin has the ability to maintain the integrity of $\mathrm{BBB}$ via regulating the expressions of occludin and $\mathrm{ZO}-1$ during glucose deprivation and hypoxia. Curcumin and curcumin-loaded PLGA nanoparticles penetrated the BBB to enter brain tissues, where it was accumulated primarily in the hippocampus. Nanotechnology markedly increased the retention time of curcumin in the hippocampus (elevated by $83 \%$ ) and cerebral cortex (elevated by 96\%) (Tsai et al., 2011). In brain microvascular endothelial cells, curcumin improved the permeability of $\mathrm{BBB}$ during hypoxia via upregulating the expression of heme oxygenase-1 (Phillips et al., 2006). All of the evidence warrant more preclinical and clinical studies for better understand the potential therapeutic benefits.

\section{CONCLUSION}

Considerable efforts are being invested to develop antineoplastic agents, but these agents have various limitations, including severe side effects and high cost. Since there are several adverse effects of currently available inhibitors of NF- $\kappa \mathrm{B}$, thus investigating the currently available naturopathic formulations can provide a perfect platform for identifying novel inhibitors of NF- $\kappa B$ considering the specific and non-specific multi-target activities of phytochemicals on several constituents of the NF- $\mathrm{kB}$ signaling pathway. The activation of NF- $\mathrm{kB}$ ensures a pro-proliferative activity in GBM. Inhibiting this pathway via suppressing the 
NF- $\kappa \mathrm{B}$ effect or specially NF- $\kappa \mathrm{B}$-inducible genes might be a promising therapeutic method to treat GBM. Numerous attempts have been made to include inhibition of NF- $\kappa \mathrm{B}$ into GBM treatment, but no precise outcome has been attained so far. Even though some naturally occurring compounds that inhibit NF- $\kappa \mathrm{B}$ signaling pathways (particularly IKK inhibitors) are available, but more specific inhibitors of IKK and other upstream kinases need to be further studied clinically to confirm their potential in patients with GBM. Various natural compounds contain auspicious NF- $\kappa \mathrm{B}$ modulatory activities in the treatment of GBM. As NF- $\kappa$ B modulators exhibited low toxic effects against normal astrocytes (which indicate their selectivity towards cancer cells), hence phytochemicals might play a role as potential agents in clinical trials, facilitating the finding of better therapy to treat GBM. In GBM patients, most of the chemotherapy trials failed partially because of the poor drug penetration across the $\mathrm{BBB}$. It has been observed that natural products might alter the permeability of $\mathrm{BBB}$ via modifying the action of its constituents. Most of these mentioned phytochemicals are yet to be studied in human clinical trials and/or cancer models for their anticancer properties, bioavailability, and biocompatibility. As compared to available synthetic inhibitors of NF- $\kappa \mathrm{B}$, these natural products possess several advantages, including efficacy and safety. Along with conventional cancer therapy, the use of these natural products as adjunctive chemotherapy might establish a better therapeutic approach. However, structural alterations of these

\section{REFERENCES}

Altmann, K. H., and Gertsch, J. (2007). Anticancer Drugs from Nature-Nnatural Products as a Unique Source of New Microtubule-Stabilizing Agents. Nat. Prod. Rep. 24, 327-357. doi:10.1039/b515619j

Ambegaokar, S. S., Wu, L., Alamshahi, K., Lau, J., Jazayeri, L., Chan, S., et al. (2003). Curcumin Inhibits Dose-Dependently and Time-Dependently Neuroglial Cell Proliferation and Growth. Neuro. Endocrinol. Lett. 24, 469-473.

Anand David, A. V., Arulmoli, R., and Parasuraman, S. (2016). Overviews of Biological Importance of Quercetin: A Bioactive Flavonoid. Pharmacogn. Rev. 10, 84-89. doi:10.4103/0973-7847.194044

Anderson, K. N., and Bejcek, B. E. (2008). Parthenolide Induces Apoptosis in Glioblastomas without Affecting NF-kappaB. J. Pharmacol. Sci. 106, 318-320. doi:10.1254/jphs.SC0060164

Arepalli, S. K., Choi, M., Jung, J. K., and Lee, H. (2015). Novel NF-Kb Inhibitors: a Patent Review (2011 - 2014). Expert Opin. Ther. Pat. 25, 319-334. doi:10.1517/ 13543776.2014.998199

Atkinson, G. P., Nozell, S. E., and Benveniste, E. T. (2010). NF-kappaB and STAT3 Signaling in Glioma: Targets for Future Therapies. Expert Rev. Neurother. 10, 575-586. doi:10.1586/ern.10.21

Atkinson, G. P., Nozell, S. E., Harrison, D. K., Stonecypher, M. S., Chen, D., and Benveniste, E. N. (2009). The Prolyl Isomerase Pin1 Regulates the NF-kappaB Signaling Pathway and Interleukin-8 Expression in Glioblastoma. Oncogene 28, 3735-3745. doi:10.1038/onc.2009.232

Aziz, M. A., Sarwar, M. S., Akter, T., Uddin, M. S., Xun, S., Zhu, Y., et al. (2021). Polyphenolic Molecules Targeting STAT3 Pathway for the Treatment of Cancer. Life Sci. 268, 118999. doi:10.1016/j.lfs.2020.118999

Bhat, K. P. L., Balasubramaniyan, V., Vaillant, B., Ezhilarasan, R., Hummelink, K., Hollingsworth, F., et al. (2013). Mesenchymal Differentiation Mediated by NF$\mathrm{Kb}$ Promotes Radiation Resistance in Glioblastoma. Cancer Cell 24, 331-346. doi:10.1016/j.ccr.2013.08.001

Bijangi-Vishehsaraei, K., Reza Saadatzadeh, M., Wang, H., Nguyen, A., Kamocka, M. M., Cai, W., et al. (2017). Sulforaphane Suppresses the Growth of phytochemicals ought to be evaluated to conceivably improve the antineoplastic property of these natural compounds. Enormous data are available to support more studies in utilizing natural compounds in GBM. Indeed, this poor prognosis requires the exploration of alternative therapeutic agents to ameliorate outcomes for the affected individuals. Prospective randomized trials are required to find the use of adjunctive natural therapies for the better targeting of resistance, to study safety profiles, and synergistically ameliorating existing therapies.

\section{AUTHOR CONTRIBUTIONS}

MU conceived of the original idea and designed the outlines of the study. MU, MK, and AM wrote the draft of the manuscript. MU and MK prepared the figures for the manuscript. MS, FN, TE, IA, AR, GA, AS, SM, and MA-D performed the literature review and aided in revising the manuscript. All authors have read and agreed to the published version of the manuscript.

\section{ACKNOWLEDGMENTS}

This work was funded by the Deanship of Scientific Research at Princess Nourah bint Abdulrahman University through the FastTrack Research Funding Program.
Glioblastoma Cells, Glioblastoma Stem Cell-like Spheroids, and Tumor Xenografts through Multiple Cell Signaling Pathways. J. Neurosurg. 127, 1219-1230. doi:10.3171/2016.8.JNS161197

Bonavia, R., Inda, M. M., Vandenberg, S., Cheng, S. Y., Nagane, M., Hadwiger, P., et al. (2012). EGFRvIII Promotes Glioma Angiogenesis and Growth through the NF-Kb, Interleukin-8 Pathway. Oncogene 31, 4054-4066. doi:10.1038/ onc. 2011.563

Braganhol, E., Tamajusuku, A. S., Bernardi, A., Wink, M. R., and Battastini, A. M. (2007). Ecto-5'-nucleotidase/CD73 Inhibition by Quercetin in the Human U138MG Glioma Cell Line. Biochim. Biophys. Acta 1770, 1352-1359. doi:10.1016/J.BBAGEN.2007.06.003

Braganhol, E., Zamin, L. L., Canedo, A. D., Horn, F., Tamajusuku, A. S., Wink, M. R., et al. (2006). Antiproliferative Effect of Quercetin in the Human U138MG Glioma Cell Line. Anticancer. Drugs 17, 663-671. doi:10.1097/ 01.CAD.0000215063.23932.02

Brassesco, M. S., Roberto, G. M., Morales, A. G., Oliveira, J. C., Delsin, L. E., Pezuk, J. A., et al. (2013). Inhibition of NF- $\kappa$ B by Dehydroxymethylepoxyquinomicin Suppresses Invasion and Synergistically Potentiates Temozolomide and $\gamma$-Radiation Cytotoxicity in Glioblastoma Cells. Chemother. Res. Pract. 2013, 593020. doi:10.1155/2013/593020

Bredel, M., Scholtens, D. M., Yadav, A. K., Alvarez, A. A., Renfrow, J. J., Chandler, J. P., et al. (2011). NFKBIA Deletion in Glioblastomas. N. Engl. J. Med. 364, 627-637. doi:10.1056/nejmoa1006312

Brunelli, D., Tavecchio, M., Falcioni, C., Frapolli, R., Erba, E., Iori, R., et al. (2010). The Isothiocyanate Produced from Glucomoringin Inhibits NF-kB and Reduces Myeloma Growth in Nude Mice In Vivo. Biochem. Pharmacol. 79, 1141-1148. doi:10.1016/j.bcp.2009.12.008

Chan, J. A., Krichevsky, A. M., and Kosik, K. S. (2005). MicroRNA-21 Is an Antiapoptotic Factor in Human Glioblastoma Cells. Cancer Res. 65, 6029-6033. doi:10.1158/0008-5472.CAN-05-0137

Chang, X., He, H., Zhu, L., Gao, J., Wei, T., Ma, Z., et al. (2015). Protective Effect of Apigenin on Freund's Complete Adjuvant-Induced Arthritis in Rats via Inhibiting P2X7/NF-Kb Pathway. Chem. Biol. Interact. 236, 41-46. doi:10.1016/j.cbi.2015.04.021 
Chaturvedi, D. (2019). "Recent Developments in the Anti-inflammatory Potential of Sesquiterpene Lactones and Their Semisynthetic Analogs", in Natural Product Drug Discovery, Discovery and Development of Anti-Inflammatory Agents from Natural Products. Editor G. Brahmachari (Amsterdam: Elsevier), 185-205.

Chen, X. J., Wu, M. Y., Li, D. H., and You, J. (2016). Apigenin Inhibits Glioma Cell Growth through Promoting microRNA-16 and Suppression of BCL-2 and Nuclear Factor-Kb/mmp-9. Mol. Med. Rep. 14, 2352-2358. doi:10.3892/ mmr.2016.5460

Chen, Y., Liu, W., Chao, T., Zhang, Y., Yan, X., Gong, Y., et al. (2008). MicroRNA21 Down-Regulates the Expression of Tumor Suppressor PDCD4 in Human Glioblastoma Cell T98G. Cancer Lett. 272, 197-205. doi:10.1016/ j.canlet.2008.06.034

Cheng, A. L., Hsu, C. H., Lin, J. K., Hsu, M. M., Ho, Y. F., Shen, T. S., et al. (2001). Phase I Clinical Trial of Curcumin, a Chemopreventive Agent, in Patients with High-Risk or Pre-malignant Lesions. Anticancer Res. 21, 2895-2900.

Cheung, K. L., and Kong, A. N. (2010). Molecular Targets of Dietary Phenethyl Isothiocyanate and Sulforaphane for Cancer Chemoprevention. AAPS J. 12, 87-97. doi:10.1208/s12248-009-9162-8

Chow, B. W., and Gu, C. (2015). The Molecular Constituents of the Blood-Brain Barrier. Trends Neurosciences 38, 598-608. doi:10.1016/J.TINS.2015.08.003

Chun, J., Choi, R. J., Khan, S., Lee, D. S., Kim, Y. C., Nam, Y. J., et al. (2012). Alantolactone Suppresses Inducible Nitric Oxide Synthase and Cyclooxygenase-2 Expression by Down-Regulating NF-Kb, MAPK and AP1 via the MyD88 Signaling Pathway in LPS-Activated RAW 264.7 Cells. Int. Immunopharmacol. 14, 375-383. doi:10.1016/j.intimp.2012.08.011

Ciafrè, S. A., Galardi, S., Mangiola, A., Ferracin, M., Liu, C. G., Sabatino, G., et al. (2005). Extensive Modulation of a Set of microRNAs in Primary Glioblastoma. Biochem. Biophys. Res. Commun. 334, 1351-1358. doi:10.1016/ j.bbrc.2005.07.030

Clarke, J. D., Dashwood, R. H., and Ho, E. (2008). Multi-targeted Prevention of Cancer by Sulforaphane. Cancer Lett. 269, 291-304. doi:10.1016/ j.canlet.2008.04.018

ClinicalTrials.gov The Effects of Ashwagandha in Endurance Exercise Performance. Available online: https://clinicaltrials.gov/ct2/show/ NCT03596307 (Accessed on Feb 15, 2021).

ClinicalTrials.gov Withania Somnifera An Immunomodulator and Antiinflammatory Agent for Schizophrenia. Available online: https://clinicaltrials. gov/ct2/show/NCT01793935 (Accessed on Feb 15, 2021).

Cooper, L. A., Kong, J., Gutman, D. A., Wang, F., Cholleti, S. R., Pan, T. C., et al. (2010). An Integrative Approach for In Silico Glioma Research. IEEE Trans. Biomed. Eng. 57, 2617-2621. doi:10.1109/TBME.2010.2060338

Coupienne, I., Bontems, S., Dewaele, M., Rubio, N., Habraken, Y., Fulda, S., et al. (2011). NF-kappaB Inhibition Improves the Sensitivity of Human Glioblastoma Cells to 5-aminolevulinic Acid-Based Photodynamic Therapy. Biochem. Pharmacol. 81, 606-616. doi:10.1016/j.bcp.2010.12.015

Cragg, G. M., Simon, J. E., Jato, J. G., and Snader, K. M. (1996). "Drug Discovery and Development at the National Cancer Institute: Potential for New Pharmaceutical Crops," in Proceedings of the Drug Discovery and Development at the National Cancer Institute: Potential for New Pharmaceutical Crops. Editor J. Janick (Arlington, VA: ASHS), 554-560.

Dhandapani, K. M., Mahesh, V. B., and Brann, D. W. (2007). Curcumin Suppresses Growth and Chemoresistance of Human Glioblastoma Cells via AP-1 and NFkappaB Transcription Factors. J. Neurochem. 102, 522-538. doi:10.1111/ j.1471-4159.2007.04633.x

Dolcet, X., Llobet, D., Pallares, J., and Matias-Guiu, X. (2005). NF-kB in Development and Progression of Human Cancer. Virchows Arch. 446, 475-482. doi:10.1007/s00428-005-1264-9

Dolecek, T. A., Propp, J. M., Stroup, N. E., and Kruchko, C. (2012). CBTRUS Statistical Report: Primary Brain and central Nervous System Tumors Diagnosed in the United States in 2005-2009. Neuro. Oncol. 14 Suppl 5, v1-49. doi:10.1093/neuonc/nos 218

El-Readi, M. Z., Eid, S., Abdelghany, A. A., Al-Amoudi, H. S., Efferth, T., and Wink, M. (2019). Resveratrol Mediated Cancer Cell Apoptosis, and Modulation of Multidrug Resistance Proteins and Metabolic Enzymes. Phytomedicine 55, 269-281. doi:10.1016/j.phymed.2018.06.046

Erdogan, S., Doganlar, O., Doganlar, Z. B., Serttas, R., Turkekul, K., Dibirdik, I., et al. (2016). The Flavonoid Apigenin Reduces Prostate Cancer CD44(+) Stem
Cell Survival and Migration through PI3K/Akt/NF-Kb Signaling. Life Sci. 162, 77-86. doi:10.1016/j.lfs.2016.08.019

Ferri, P., Angelino, D., Gennari, L., Benedetti, S., Ambrogini, P., Grande, P. D., et al. (2015). Enhancement of Flavonoid Ability to Cross the Blood-Brain Barrier of Rats by Co-administration with $\alpha$-tocopherol. Food Funct. 6, 394-400. doi:10.1039/C4FO00817K

Fratantonio, D., Molonia, M. S., Bashllari, R., Muscarà, C., Ferlazzo, G., Costa, G., et al. (2019). Curcumin Potentiates the Antitumor Activity of Paclitaxel in Rat Glioma C6 Cells. Phytomedicine 55, 23-30. doi:10.1016/j.phymed.2018.08.009

Friedmann-Morvinski, D., Narasimamurthy, R., Xia, Y., Myskiw, C., Soda, Y., and Verma, I. M. (2016). Targeting NF-Kb in Glioblastoma: A Therapeutic Approach. Sci. Adv. 2, e1501292. doi:10.1126/sciadv.1501292

Fukushima, T., Kawaguchi, M., Yorita, K., Tanaka, H., Takeshima, H., Umezawa, K., et al. (2012). Antitumor Effect of Dehydroxymethylepoxyquinomicin, a Small Molecule Inhibitor of Nuclear Factor-Kb, on Glioblastoma. Neuro. Oncol. 14, 19-28. doi:10.1093/neuonc/nor168

Furnari, F. B., Fenton, T., Bachoo, R. M., Mukasa, A., Stommel, J. M., Stegh, A., et al. (2007). Malignant Astrocytic Glioma: Genetics, Biology, and Paths to Treatment. Genes Dev. 21, 2683-2710. doi:10.1101/gad.1596707

Gao, X., Deeb, D., Jiang, H., Liu, Y. B., Dulchavsky, S. A., and Gautam, S. C. (2005). Curcumin Differentially Sensitizes Malignant Glioma Cells to TRAIL/Apo2Lmediated Apoptosis through Activation of Procaspases and Release of Cytochrome C from Mitochondria. J. Exp. Ther. Oncol. 5, 39-48.

Gerstner, E. R., and Fine, R. L. (2007). Increased Permeability of the Blood-Brain Barrier to Chemotherapy in Metastatic Brain Tumors: Establishing a Treatment Paradigm. J. Clin. Oncol. 25, 2306-2312. doi:10.1200/JCO.2006.10.0677

Gill, J. S., Zhu, X., Moore, M. J., Lu, L., Yaszemski, M. J., and Windebank, A. J. (2002). Effects of NFkappaB Decoy Oligonucleotides Released from Biodegradable Polymer Microparticles on a Glioblastoma Cell Line. Biomaterials 23, 2773-2781. doi:10.1016/S0142-9612(02)00013-3

Gilmore, T. D. (2006). Introduction to NF-kappaB: Players, Pathways, Perspectives. Oncogene 25, 6680-6684. doi:10.1038/sj.onc.1209954

Grivennikov, S. I., and Karin, M. (2010). Dangerous Liaisons: STAT3 and NFkappaB Collaboration and Crosstalk in Cancer. Cytokine Growth Factor. Rev. 21, 11-19. doi:10.1016/j.cytogfr.2009.11.005

Grivennikov, S. I., and Karin, M. (2011). Inflammatory Cytokines in Cancer: Tumour Necrosis Factor and Interleukin 6 Take the Stage. Ann. Rheum. Dis. 70 Suppl 1, i104-8. doi:10.1136/ard.2010.140145

Guo, W., Li, A., Jia, Z., Yuan, Y., Dai, H., and Li, H. (2013). Transferrin Modified PEG-PLA-Resveratrol Conjugates: In Vitro and In Vivo Studies for Glioma. Eur. J. Pharmacol. 718, 41-47. doi:10.1016/J.EJPHAR.2013.09.034

Guo, Z., Wang, H., Wei, J., Han, L., and Li, Z. (2019). Sequential Treatment of Phenethyl Isothiocyanate Increases Sensitivity of Temozolomide Resistant Glioblastoma Cells by Decreasing Expression of MGMT via NF-Kb Pathway. Am. J. Transl. Res. 11, 696-708.

Haffner, M. C., Berlato, C., and Doppler, W. (2006). Exploiting Our Knowledge of NF-kappaB Signaling for the Treatment of Mammary Cancer. J. Mammary Gland Biol. Neoplasia 11, 63-73. doi:10.1007/s10911-006-9013-5

Hayashi, S., Yamamoto, M., Ueno, Y., Ikeda, K., Ohshima, K., Soma, G., et al. (2001). Expression of Nuclear Factor-Kappa B, Tumor Necrosis Factor Receptor Type 1, and C-Myc in Human Astrocytomas. Neurol. Med. Chir (Tokyo) 41, 187-195. doi:10.2176/nmc.41.187

Hegi, M. E., Diserens, A. C., Gorlia, T., Hamou, M. F., de Tribolet, N., Weller, M., et al. (2005). MGMT Gene Silencing and Benefit from Temozolomide in Glioblastoma. N. Engl. J. Med. 352, 997-1003. doi:10.1056/nejmoa043331

Heptinstall, S. (1988). Feverfew--an Ancient Remedy for Modern Times?. J. R. Soc. Med. 81, 373-374. doi:10.1177/014107688808100701

Hjelmeland, A. B., Wu, Q., Wickman, S., Eyler, C., Heddleston, J., Shi, Q., et al. (2010). Targeting A20 Decreases Glioma Stem Cell Survival and Tumor Growth. Plos Biol. 8, e1000319. doi:10.1371/journal.pbio.1000319

Holmes, K. M., Annala, M., Chua, C. Y., Dunlap, S. M., Liu, Y., Hugen, N., et al. (2012). Insulin-like Growth Factor-Binding Protein 2-driven Glioma Progression Is Prevented by Blocking a Clinically Significant Integrin, Integrin-Linked Kinase, and NF-Kb Network. Proc. Natl. Acad. Sci. U. S. A. 109, 3475-3480. doi:10.1073/pnas.1120375109

Hua, D., Ding, D., Han, X., Zhang, W., Zhao, N., Foltz, G., et al. (2012). Human miR-31 Targets Radixin and Inhibits Migration and Invasion of Glioma Cells. Oncol. Rep. 27, 700-706. doi:10.3892/or.2011.1555 
Huang, H., Lin, H., Zhang, X., and Li, J. (2012). Resveratrol Reverses Temozolomide Resistance by Downregulation of MGMT in T98G Glioblastoma Cells by the NF-kb-dependent Pathway. Oncol. Rep. 27, 2050-2056. doi:10.3892/or.2012.1715

Huang, M., Lu, J. J., and Ding, J. (2021). Natural Products in Cancer Therapy: Past, Present and Future. Nat. Prod. Bioprospect 11, 5-13. doi:10.1007/s13659-02000293-7

Huang, P., Rani, M. R., Ahluwalia, M. S., Bae, E., Prayson, R. A., Weil, R. J., et al. (2012). Endothelial Expression of TNF Receptor-1 Generates a Proapoptotic Signal Inhibited by Integrin $\alpha 6 \beta 1$ in Glioblastoma. Cancer Res. 72, 1428-1437. doi:10.1158/0008-5472.CAN-11-2621

Huang, T. Y., Chang, W. C., Wang, M. Y., Yang, Y. R., and Hsu, Y. C. (2012). Effect of Sulforaphane on Growth Inhibition in Human Brain Malignant Glioma GBM 8401 Cells by Means of Mitochondrial- and MEK/ERK-Mediated Apoptosis Pathway. Cell Biochem. Biophys. 63, 247-259. doi:10.1007/s12013012-9360-3

Hummel, R., Maurer, J., and Haier, J. (2011). MicroRNAs in Brain Tumors : a New Diagnostic and Therapeutic Perspective?. Mol. Neurobiol. 44, 223-234. doi:10.1007/s12035-011-8197-x

Huse, J. T., and Holland, E. C. (2010). Targeting Brain Cancer: Advances in the Molecular Pathology of Malignant Glioma and Medulloblastoma. Nat. Rev. Cancer 10, 319-331. doi:10.1038/nrc2818

Huse, J. T., Phillips, H. S., and Brennan, C. W. (2011). Molecular Subclassification of Diffuse Gliomas: Seeing Order in the Chaos. Glia 59, 1190-1199. doi:10.1002/glia.21165

Jacobs, V. L., Landry, R. P., Liu, Y., Romero-Sandoval, E. A., and De Leo, J. A. (2012). Propentofylline Decreases Tumor Growth in a Rodent Model of Glioblastoma Multiforme by a Direct Mechanism on Microglia. Neuro. Oncol. 14, 119-131. doi:10.1093/NEUONC/NOR194

Jeandet, P., Vannozzi, A., Sobarzo-Sánchez, E., Uddin, M. S., Bru, R., MartínezMárquez, A., et al. (2021). Phytostilbenes as Agrochemicals: Biosynthesis, Bioactivity, Metabolic Engineering and Biotechnology. Nat. Prod. Rep. 38, 1282-1329. doi:10.1039/d0np00030b

Jiang, G., Zhang, L., Wang, J., and Zhou, H. (2016). Baicalein Induces the Apoptosis of U251 Glioblastoma Cell Lines via the NF-kB-P65-Mediated Mechanism. Anim. Cell Syst. 20, 296-302. doi:10.1080/19768354.2016.1229216

Jiang, L., Lin, C., Song, L., Wu, J., Chen, B., Ying, Z., et al. (2012). MicroRNA-30e* promotes human glioma cell invasiveness in an orthotopic xenotransplantation model by disrupting the NF- $\mathrm{kB} / \mathrm{I} \kappa \mathrm{B} a$ negative feedback loop. J. Clin. Invest. 122, 33-47. doi:10.1172/JCI58849

Jiao, Y., Li, H., Liu, Y., Guo, A., Xu, X., Qu, X., et al. (2015). Resveratrol Inhibits the Invasion of Glioblastoma-Initiating Cells via Down-Regulation of the PI3K/ Akt/NF-Kb Signaling Pathway. Nutrients 7, 4383-4402. doi:10.3390/ nu7064383

Johnsen, K. B., Burkhart, B., Melander, F., Kempen, P. J., Vejlebo, J. B., Siupka, P., et al. (2017). Targeting Transferrin Receptors at the Blood-Brain Barrier Improves the Uptake of Immunoliposomes and Subsequent Cargo Transport into the Brain Parenchyma. Sci. Rep. 7. doi:10.1038/S41598-01711220-1

Kargiotis, O., Rao, J. S., and Kyritsis, A. P. (2006). Mechanisms of Angiogenesis in Gliomas. J. Neurooncol. 78, 281-293. doi:10.1007/s11060-005-9097-6

Karlebach, G., and Shamir, R. (2010). Minimally Perturbing a Gene Regulatory Network to Avoid a Disease Phenotype: The Glioma Network as a Test Case. BMC Syst. Biol. 4, 15. doi:10.1186/1752-0509-4-15

Khan, M., Yi, F., Rasul, A., Li, T., Wang, N., Gao, H., et al. (2012). Alantolactone Induces Apoptosis in Glioblastoma Cells via GSH Depletion, ROS Generation, and Mitochondrial Dysfunction. IUBMB Life 64, 783-794. doi:10.1002/ iub.1068

Kiekow, C. J., Figueiró, F., Dietrich, F., Vechia, L. D., Pires, E. N., Jandrey, E. H., et al. (2016). Quercetin Derivative Induces Cell Death in Glioma Cells by Modulating NF-Kb Nuclear Translocation and Caspase-3 Activation. Eur. J. Pharm. Sci. 84, 116-122. doi:10.1016/J.EJPS.2016.01.019

Kiekow, C. J., Figueiró, F., Dietrich, F., Vechia, L. D., Pires, E. N., Jandrey, E. H., et al. (2016). Quercetin Derivative Induces Cell Death in Glioma Cells by Modulating NF-Kb Nuclear Translocation and Caspase-3 Activation. Eur. J. Pharm. Sci. 84, 116-122. doi:10.1016/j.ejps.2016.01.019

Kim, S. Y., Jung, S. H., and Kim, H. S. (2005). Curcumin Is a Potent Broad Spectrum Inhibitor of Matrix Metalloproteinase Gene Expression in Human
Astroglioma Cells. Biochem. Biophys. Res. Commun. 337, 510-516. doi:10.1016/ j.bbrc.2005.09.079

Kumar, R., Harilal, S., Parambi, D. G. T., Narayanan, S. E., Uddin, M. S., Marathakam, A., et al. (2020). Fascinating Chemo Preventive story of Wogonin: A Chance to Hit on the Head in Cancer Treatment. Curr. Pharm. Des. 26. doi:10.2174/1385272824999200427083040

Kumar, R., Lal, N., Nemaysh, V., and Luthra, P. M. (2018). Demethoxycurcumin Mediated Targeting of MnSOD Leading to Activation of Apoptotic Pathway and Inhibition of Akt/NF-Kb Survival Signalling in Human Glioma U87 MG Cells. Toxicol. Appl. Pharmacol. 345, 75-93. doi:10.1016/j.taap.2018.02.020

Kwok, B. H., Koh, B., Ndubuisi, M. I., Elofsson, M., and Crews, C. M. (2001). The Anti-inflammatory Natural Product Parthenolide from the Medicinal Herb Feverfew Directly Binds to and Inhibits IkappaB Kinase. Chem. Biol. 8, 759-766. doi:10.1016/S1074-5521(01)00049-7

Lakomy, R., Sana, J., Hankeova, S., Fadrus, P., Kren, L., Lzicarova, E., et al. (2011). MiR-195, miR-196b, miR-181c, miR-21 Expression Levels and O-6Methylguanine-DNA Methyltransferase Methylation Status Are Associated with Clinical Outcome in Glioblastoma Patients. Cancer Sci. 102, 2186-2190. doi:10.1111/j.1349-7006.2011.02092.x

Lan, F., Yang, Y., Han, J., Wu, Q., Yu, H., and Yue, X. (2016). Sulforaphane Reverses Chemo-Resistance to Temozolomide in Glioblastoma Cells by NF-kbdependent Pathway Downregulating MGMT Expression. Int. J. Oncol. 48, 559-568. doi:10.3892/IJO.2015.3271

Lécuyer, M.-A., Kebir, H., and Prat, A. (2016), Glial Influences on BBB Functions and Molecular Players in Immune Cell Trafficking. Biochim. Biophys. Acta 1862, 472-482. doi:10.1016/J.BBADIS.2015.10.004

Lee, C. S., Cho, H. J., Jeong, Y. J., Shin, J. M., Park, K. K., Park, Y. Y., et al. (2015). Isothiocyanates Inhibit the Invasion and Migration of C6 Glioma Cells by Blocking FAK/JNK-mediated MMP-9 Expression. Oncol. Rep. 34, 2901-2908. doi:10.3892/or.2015.4292

Lenzi, M., Fimognari, C., and Hrelia, P. (2014). Sulforaphane as a Promising Molecule for Fighting Cancer. Cancer Treat. Res. 159, 207-223. doi:10.1007/ 978-3-642-38007-5_12

Li, C., Zhou, Y., Peng, X., Du, L., Tian, H., Yang, G., et al. (2014). Sulforaphane Inhibits Invasion via Activating ERK1/2 Signaling in Human Glioblastoma U87MG and U373MG Cells. PLoS One 9, e90520. doi:10.1371/ JOURNAL.PONE.0090520

Li, F., and Sethi, G. (2010). Targeting Transcription Factor NF-kappaB to Overcome Chemoresistance and Radioresistance in Cancer Therapy. Biochim. Biophys. Acta 1805, 167-180. doi:10.1016/j.bbcan.2010.01.002

Li, Y., Li, W., Yang, Y., Lu, Y., He, C., Hu, G., et al. (2009). MicroRNA-21 Targets LRRFIP1 and Contributes to VM-26 Resistance in Glioblastoma Multiforme. Brain Res. 1286, 13-18. doi:10.1016/j.brainres.2009.06.053

Li, Y., Zhou, S., Li, J., Sun, Y., Hasimu, H., Liu, R., et al. (2015). Quercetin Protects Human Brain Microvascular Endothelial Cells from Fibrillar $\beta$-amyloid1-40induced Toxicity. Acta Pharm. Sin. B 5, 47-54. doi:10.1016/J.APSB.2014.12.003

Lin, S. R., Chang, C. H., Hsu, C. F., Tsai, M. J., Cheng, H., Leong, M. K., et al. (2020). Natural Compounds as Potential Adjuvants to Cancer Therapy: Preclinical Evidence. Br. J. Pharmacol. 177, 1409-1423. doi:10.1111/bph.14816

Liu, H., Dong, Y., Gao, Y., Du, Z., Wang, Y., Cheng, P., et al. (2016). The Fascinating Effects of Baicalein on Cancer: A Review. Int. J. Mol. Sci. 17. doi:10.3390/ijms17101681

Liu, Y., Tang, Z. G., Lin, Y., Qu, X. G., Lv, W., Wang, G. B., et al. (2017). Effects of Quercetin on Proliferation and Migration of Human Glioblastoma U251 Cells. Biomed. Pharmacother. 92, 33-38. doi:10.1016/j.biopha.2017.05.044

Liu, Y., Tang, Z. G., Yang, J. Q., Zhou, Y., Meng, L. H., Wang, H., et al. (2017). Low Concentration of Quercetin Antagonizes the Invasion and Angiogenesis of Human Glioblastoma U251 Cells. Onco. Targets Ther. 10, 4023-4028. doi:10.2147/OTT.S136821

Mann, J. (2002). Natural Products in Cancer Chemotherapy: Past, Present and Future. Nat. Rev. Cancer 2, 143-148. doi:10.1038/nrc723

McFarland, B. C., Hong, S. W., Rajbhandari, R., Twitty, G. B., Gray, G. K., Yu, H., et al. (2013). NF- $\mathrm{kB}$-induced IL-6 Ensures STAT3 Activation and Tumor Aggressiveness in Glioblastoma. PLoS One 8, e78728. doi:10.1371/ journal.pone. 0078728

Mitsiogianni, M., Koutsidis, G., Mavroudis, N., Trafalis, D. T., Botaitis, S., Franco, R., et al. (2019). The Role of Isothiocyanates as Cancer Chemo-Preventive, 
Chemo-Therapeutic and Anti-melanoma Agents. Antioxidants (Basel) 8. doi:10.3390/antiox8040106

Nakabayashi, H., and Shimizu, K. (2012). Involvement of Akt/NF-Kb Pathway in Antitumor Effects of Parthenolide on Glioblastoma Cells In Vitro and In Vivo. BMC Cancer 12, 453. doi:10.1186/1471-2407-12-453

Noch, E. K., Ramakrishna, R., and Magge, R. (2018). Challenges in the Treatment of Glioblastoma: Multisystem Mechanisms of Therapeutic Resistance. World Neurosurg. 116, 505-517. doi:10.1016/J.WNEU.2018.04.022

Nogueira, L., Ruiz-Ontañon, P., Vazquez-Barquero, A., Lafarga, M., Berciano, M. T., Aldaz, B., et al. (2011). Blockade of the NFkB Pathway Drives Differentiating Glioblastoma-Initiating Cells into Senescence Both In Vitro and In Vivo. Oncogene 30, 3537-3548. doi:10.1038/onc.2011.74

Nogueira, L., Ruiz-Ontañon, P., Vazquez-Barquero, A., Moris, F., and FernandezLuna, J. L. (2011). The NFkB Pathway: a Therapeutic Target in Glioblastoma. Oncotarget 2, 646-653. doi:10.18632/oncotarget.322

Nozell, S., Laver, T., Moseley, D., Nowoslawski, L., De Vos, M., Atkinson, G. P., et al. (2008). The ING4 Tumor Suppressor Attenuates NF-kappaB Activity at the Promoters of Target Genes. Mol. Cel. Biol. 28, 6632-6645. doi:10.1128/ mcb.00697-08

Obermeier, B., Daneman, R., and Ransohoff, R. M. (2013). Development, Maintenance and Disruption of the Blood-Brain Barrier. Nat. Med. 19, 1584-1596. doi:10.1038/NM.3407

Papagiannakopoulos, T., Shapiro, A., and Kosik, K. S. (2008). MicroRNA-21 Targets a Network of Key Tumor-Suppressive Pathways in Glioblastoma Cells. Cancer Res. 68, 8164-8172. doi:10.1158/0008-5472.CAN-08-1305

Park, M. H., Ahn, B. H., Hong, Y. K., and Min, do. S. (2009). Overexpression of Phospholipase D Enhances Matrix Metalloproteinase-2 Expression and Glioma Cell Invasion via Protein Kinase C and Protein Kinase A/NF-kappaB/Sp1mediated Signaling Pathways. Carcinogenesis 30, 356-365. doi:10.1093/carcin/ bgn 287

Park, M. H., and Hong, J. T. (2016). Roles of NF-Kb in Cancer and Inflammatory Diseases and Their Therapeutic Approaches. Cells 5, 15. doi:10.3390/ cells5020015

Park, M. H., and Min, do. S. (2011). Quercetin-induced Downregulation of Phospholipase D1 Inhibits Proliferation and Invasion in U87 Glioma Cells. Biochem. Biophys. Res. Commun. 412, 710-715. doi:10.1016/j.bbrc.2011.08.037

Patanè, M., Porrati, P., Bottega, E., Morosini, S., Cantini, G., Girgenti, V., et al. (2013). Frequency of NFKBIA Deletions Is Low in Glioblastomas and Skewed in Glioblastoma Neurospheres. Mol. Cancer 12, 160. doi:10.1186/1476-459812-160

Phillips, H. S., Kharbanda, S., Chen, R., Forrest, W. F., Soriano, R. H., Wu, T. D., et al. (2006). Molecular Subclasses of High-Grade Glioma Predict Prognosis, Delineate a Pattern of Disease Progression, and Resemble Stages in Neurogenesis. Cancer Cell 9, 157-173. doi:10.1016/j.ccr.2006.02.019

Phuphanich, S., Supko, J. G., Carson, K. A., Grossman, S. A., Burt Nabors, L., Mikkelsen, T., et al. (2010). Phase 1 Clinical Trial of Bortezomib in Adults with Recurrent Malignant Glioma. J. Neurooncol. 100, 95-103. doi:10.1007/s11060010-0143-7

Prawan, A., Saw, C. L., Khor, T. O., Keum, Y. S., Yu, S., Hu, L., et al. (2009). AntiNF-kappaB and Anti-inflammatory Activities of Synthetic Isothiocyanates: Effect of Chemical Structures and Cellular Signaling. Chem. Biol. Interact. 179, 202-211. doi:10.1016/j.cbi.2008.12.014

Puliyappadamba, V. T., Chakraborty, S., Chauncey, S. S., Li, L., Hatanpaa, K. J., Mickey, B., et al. (2013). Opposing Effect of EGFRWT on EGFRvIII-Mediated NF-Kb Activation with RIP1 as a Cell Death Switch. Cell Rep 4, 764-775. doi:10.1016/j.celrep.2013.07.025

Puliyappadamba, V. T., Hatanpaa, K. J., Chakraborty, S., and Habib, A. A. (2014). The Role of NF-Kb in the Pathogenesis of Glioma. Mol. Cel. Oncol. 1, e963478. doi:10.4161/23723548.2014.963478

Qin, Y., Zhao, D., Zhou, H. G., Wang, X. H., Zhong, W. L., Chen, S., et al. (2016). Apigenin Inhibits NF-Kb and Snail Signaling, EMT and Metastasis in Human Hepatocellular Carcinoma. Oncotarget 7, 41421-41431. doi:10.18632/ oncotarget.9404

Rasul, A., Khan, M., Ali, M., Li, J., and Li, X. (2013). Targeting Apoptosis Pathways in Cancer with Alantolactone and Isoalantolactone. ScientificWorldJournal 2013, 248532. doi:10.1155/2013/248532
Ren, Z., Wang, L., Cui, J., Huoc, Z., Xue, J., Cui, H., et al. (2013). Resveratrol Inhibits NF-kB Signaling through Suppression of P65 and IkappaB Kinase Activities. Pharmazie 68, 689-694.

Reyes-Farias, M., and Carrasco-Pozo, C. (2019). The Anti-cancer Effect of Quercetin: Molecular Implications in Cancer Metabolism. Int. J. Mol. Sci. 20, 3177. doi:10.3390/ijms20133177

Richmond, A., and Yang, J. (2016). The Role of NF-kB in Modulating Antitumor Immunity. Oncoimmunology 5, e1005522. doi:10.1080/ 2162402X.2015.1005522

Robe, P. A., Bentires-Alj, M., Bonif, M., Rogister, B., Deprez, M., Haddada, H., et al. (2004). In Vitro and In Vivo Activity of the Nuclear Factor-kappaB Inhibitor Sulfasalazine in Human Glioblastomas. Clin. Cancer Res. 10, 5595-5603. doi:10.1158/1078-0432.CCR-03-0392

Saberi-Karimian, M., Katsiki, N., Caraglia, M., Boccellino, M., Majeed, M., and Sahebkar, A. (2019). Vascular Endothelial Growth Factor: An Important Molecular Target of Curcumin. Crit. Rev. Food Sci. Nutr. 59, 299-312. doi:10.1080/10408398.2017.1366892

Schacter, L. (1996). Etoposide Phosphate: what, Why, where, and How? Semin. Oncol. 23, 1-7.

Seo, M. B., Lee, S. K., Jeon, Y. J., and Im, J. S. (2011). Inhibition of P65 Nuclear Translocation by Baicalein. Toxicol. Res. 27, 71-76. doi:10.5487/ TR.2011.27.2.071

Shukla, S., Pia Patric, I. R., Thinagararjan, S., Srinivasan, S., Mondal, B., Hegde, A. S., et al. (2013). A DNA Methylation Prognostic Signature of Glioblastoma: Identification of NPTX2-PTEN-NF-Kb Nexus. Cancer Res. 73, 6563-6573. doi:10.1158/0008-5472.CAN-13-0298

Song, L., Lin, C., Gong, H., Wang, C., Liu, L., Wu, J., et al. (2013). miR-486 Sustains NF-Kb Activity by Disrupting Multiple NF-Kb-Negative Feedback Loops. Cell Res. 23, 274-289. doi:10.1038/cr.2012.174

Song, L., Liu, L., Wu, Z., Li, Y., Ying, Z., Lin, C., et al. (2012). TGF- $\beta$ Induces miR182 to Sustain NF-Kb Activation in Glioma Subsets. J. Clin. Invest. 122, 3563-3578. doi:10.1172/JCI62339

Srinivasan, S., Patric, I. R., and Somasundaram, K. (2011). A Ten-microRNA Expression Signature Predicts Survival in Glioblastoma. PLoS One 6, el7438. doi:10.1371/journal.pone.0017438

Stiles, C. D., and Rowitch, D. H. (2008). Glioma Stem Cells: A Midterm Exam. Neuron. 58, 832-846. doi:10.1016/j.neuron.2008.05.031

Subedi, L., Venkatesan, R., and Kim, S. Y. (2017). Neuroprotective and Antiinflammatory Activities of Allyl Isothiocyanate through Attenuation of JNK/ NF-кB/TNF- $\alpha$ Signaling. Int. J. Mol. Sci. 18. doi:10.3390/ijms18071423

Sun, S. C. (2011). Non-canonical NF-Kb Signaling Pathway. Cel. Res. 21, 71-85. doi:10.1038/cr.2010.177

Tanaka, K., Babic, I., Nathanson, D., Akhavan, D., Guo, D., Gini, B., et al. (2011). Oncogenic EGFR Signaling Activates an mTORC2-NF-Kb Pathway that Promotes Chemotherapy Resistance. Cancer Discov. 1, 524-538. doi:10.1158/2159-8290.CD-11-0124

Tang, W., Liang, R., Duan, Y., Shi, Q., Liu, X., and Liao, Y. (2017). PLD1 Overexpression Promotes Invasion and Migration and Function as a Risk Factor for Chinese Glioma Patients. Oncotarget 8, 57039-57046. doi:10.18632/ oncotarget.18961

Taniguchi, K., and Karin, M. (2018). NF-kB, Inflammation, Immunity and Cancer: Coming of Age. Nat. Rev. Immunol. 18, 309-324. doi:10.1038/nri.2017.142

Tellingen, v. T., Yetkin-Arik, B., Gooijer, M. C., Wesseling, P., Wurdinger, T., and Vries, H. E. (2015). Overcoming the Blood-Brain Tumor Barrier for Effective Glioblastoma Treatment. Drug Resist. Updat. 19, 1-12. doi:10.1016/ J.DRUP.2015.02.002

Tilstra, J. S., Clauson, C. L., Niedernhofer, L. J., and Robbins, P. D. (2011). NF-kB in Aging and Disease. Aging Dis. 2, 449-465.

Tsai, Y. M., Chien, C-F., Lin, L-C., and Tsai, T-H. (2011). Curcumin and its NanoFormulation: the Kinetics of Tissue Distribution and Blood-Brain Barrier Penetration. Int. J. Pharm. 416, 331-338. doi:10.1016/J.IJPHARM.2011.06.030

Uddin, M. S., Hasana, S., Ahmad, J., Hossain, M. F., Rahman, M. M., Behl, T., et al. (2021). Anti-Neuroinflammatory Potential of Polyphenols by Inhibiting NF-Kb to Halt Alzheimer's Disease. Curr. Pharm. Des. 27, 402-414. doi:10.2174/ 1381612826666201118092422

Uddin, M. S., Mamun, A. A., Jakaria, M., Thangapandiyan, S., Ahmad, J., Rahman, M. A., et al. (2020). Emerging Promise of Sulforaphane-Mediated Nrf2 
Signaling cascade against Neurological Disorders. Sci. Total Environ. 707, 135624. doi:10.1016/j.scitotenv.2019.135624

Uddin, M. S., Mamun, A. A., Alghamdi, B. S., Tewari, D., Jeandet, P., Sarwar, M. S., et al. (2020). Epigenetics of Glioblastoma Multiforme: From Molecular Mechanisms to Therapeutic Approaches. Semin. Cancer Biol. doi:10.1016/ j.semcancer.2020.12.015

Varsha, K., Sharma, A., Kaur, A., Madan, J., Pandey, R. S., Jain, U. K., et al. (2017). "Natural Plant-Derived Anticancer Drugs Nanotherapeutics: A Review on Preclinical to Clinical Success," in Natural Product Drug Discovery, Discovery and Development of Anti-Inflammatory Agents from Natural Products. Editor A. Ficai and A. M. Grumezescu (Amsterdam: Elsevier), 775-809.

Verhaak, R. G., Hoadley, K. A., Purdom, E., Wang, V., Qi, Y., Wilkerson, M. D., et al. (2010). Integrated Genomic Analysis Identifies Clinically Relevant Subtypes of Glioblastoma Characterized by Abnormalities in PDGFRA, IDH1, EGFR, and NF1. Cancer Cell 17, 98-110. doi:10.1016/j.ccr.2009.12.020

Vervandier-Fasseur, D., and Latruffe, N. (2019). The Potential Use of Resveratrol for Cancer Prevention. Molecules 24. doi:10.3390/molecules24244506

Vijayakumar, M. R., Vajanthri, K. Y., Balavigneswaran, C. K., Mahto, S. K., Mishra, N., Muthu, M. S., et al. (2016). Pharmacokinetics, Biodistribution, In Vitro Cytotoxicity and Biocompatibility of Vitamin E TPGS Coated Trans Resveratrol Liposomes. Colloids Surf. B. Biointerfaces 145, 479-491. doi:10.1016/J.COLSURFB.2016.05.037

Wang, C.-N., Shiao, Y.-J., Lin, Y.-L., and Chen, C.-F. (1999). Nepalolide A Inhibits the Expression of Inducible Nitric Oxide Synthase by Modulating the Degradation of IкB- $\alpha$ and IкB- $\beta$ in C6 Glioma Cells and Rat Primary Astrocytes. Br. J. Pharmacol. 128, 345-356. doi:10.1038/sj.bjp.0702785

Wang, S., Jiao, B., Geng, S., Song, J., Liang, Z., and Lu, S. (2014). Concomitant microRNA-31 Downregulation and Radixin Upregulation Predicts Advanced Tumor Progression and Unfavorable Prognosis in Patients with Gliomas. J. Neurol. Sci. 338, 71-76. doi:10.1016/j.jns.2013.12.019

Wang, X., Yu, Z., Wang, C., Cheng, W., Tian, X., Huo, X., et al. (2017). Alantolactone, a Natural Sesquiterpene Lactone, Has Potent Antitumor Activity against Glioblastoma by Targeting IKK $\beta$ Kinase Activity and Interrupting NF-Kb/cox-2-Mediated Signaling Cascades. J. Exp. Clin. Cancer Res. 36, 93. doi:10.1186/s13046-017-0563-8

Wang, Y-F., Gu, Y-T., Qin, G-H., Zhong, L., and Meng, Y-N. (2013). Curcumin Ameliorates the Permeability of the Blood-Brain Barrier during Hypoxia by Upregulating Heme Oxygenase-1 Expression in Brain Microvascular Endothelial Cells. J. Mol. Neurosci. 51, 344-351. doi:10.1007/S12031-0139989-4

Wei, W., Huang, H., Zhao, S., Liu, W., Liu, C. X., Chen, L., et al. (2013). Alantolactone Induces Apoptosis in Chronic Myelogenous Leukemia Sensitive or Resistant to Imatinib through NF-Kb Inhibition and Bcr/Abl Protein Deletion. Apoptosis 18, 1060-1070. doi:10.1007/s10495-013-0854-2

Wei, H., Wang, S., Zhen, L., Yang, Q., Wu, Z., Lei, X., et al. (2015). Resveratrol attenuates the blood-brain barrier dysfunction by regulation of the MMP-9/ TIMP-1 balance after cerebral ischemia reperfusion in rats. J. Mol. Neurosci. 55 (4), 872-879. doi:10.1007/s12031-014-0441-12

Westhoff, M. A., Zhou, S., Nonnenmacher, L., Karpel-Massler, G., Jennewein, C., Schneider, M., et al. (2013). Inhibition of NF-Kb Signaling Ablates the Invasive Phenotype of Glioblastoma. Mol. Cancer Res. 11, 1611-1623. doi:10.1158/15417786.MCR-13-0435-T

Wu, H., Liu, Q., Cai, T., Chen, Y.-D., and Wang, Z.-F. (2015). Induction of microRNA-146a Is Involved in Curcumin-Mediated Enhancement of Temozolomide Cytotoxicity against Human Glioblastoma. Mol. Med. Rep. 12, 5461-5466. doi:10.3892/MMR.2015.4087

Xia, H., Yan, Y., Hu, M., Wang, Y., Wang, Y., Dai, Y., et al. (2013). MiR-218 Sensitizes Glioma Cells to Apoptosis and Inhibits Tumorigenicity by Regulating ECOP-Mediated Suppression of NF-Kb Activity. Neuro. Oncol. 15, 413-422. doi:10.1093/neuonc/nos296

Xia, Y., Shen, S., and Verma, I. M. (2014). NF-kB, an Active Player in Human Cancers. Cancer Immunol. Res. 2, 823-830. doi:10.1158/2326-6066.CIR-140112

Xu, C., Shen, G., Chen, C., Gélinas, C., and Kong, A.-N. T. (2005). Suppression of $\mathrm{NF}-\mathrm{Kb}$ and NF-Kb-Regulated Gene Expression by Sulforaphane and PEITC through IкBa, IKK Pathway in Human Prostate Cancer PC-3 Cells. Oncogene 24, 4486-4495. doi:10.1038/sj.onc. 1208656

Yan, X., Qi, M., Li, P., Zhan, Y., and Shao, H. (2017). Apigenin in Cancer Therapy: Anti-cancer Effects and Mechanisms of Action. Cell Biosci. 7, 50. doi:10.1186/ s13578-017-0179-x

Yang, G., Han, D., Chen, X., Zhang, D., Wang, L., Shi, C., et al. (2014). MiR-196a Exerts its Oncogenic Effect in Glioblastoma Multiforme by Inhibition of ІкBa Both In Vitro and In Vivo. Neuro. Oncol. 16, 652-661. doi:10.1093/neuonc/ not 307

Yang, W., Xia, Y., Cao, Y., Zheng, Y., Bu, W., Zhang, L., et al. (2012). EGFRinduced and $\mathrm{PKC} \varepsilon$ Monoubiquitylation-dependent NF-Kb Activation Upregulates PKM2 Expression and Promotes Tumorigenesis. Mol. Cel. 48, 771-784. doi:10.1016/j.molcel.2012.09.028

Yin, D., Zhou, H., Kumagai, T., Liu, G., Ong, J. M., Black, K. L., et al. (2005). Proteasome Inhibitor PS-341 Causes Cell Growth Arrest and Apoptosis in Human Glioblastoma Multiforme (GBM). Oncogene 24, 344-354. doi:10.1038/ sj.onc. 1208225

Yu, X., Liu, Y., Wang, Y., Mao, X., Zhang, Y., and Xia, J. (2018). Baicalein Induces Cervical Cancer Apoptosis through the NF-Kb Signaling Pathway. Mol. Med. Rep. 17, 5088-5094. doi:10.3892/mmr.2018.8493

Yu, Z., Chen, Y., Wang, S., Li, P., Zhou, G., and Yuan, Y. (2018). Inhibition of NF$\mathrm{Kb}$ Results in Anti-glioma Activity and Reduces Temozolomide-Induced Chemoresistance by Down-Regulating MGMT Gene Expression. Cancer Lett. 428, 77-89. doi:10.1016/j.canlet.2018.04.033

Zaplatic, E., Bule, M., Shah, S. Z. A., Uddin, M. S., and Niaz, K. (2019). Molecular Mechanisms Underlying Protective Role of Quercetin in Attenuating Alzheimer's Disease. Life Sci. 224, 109-119. doi:10.1016/j.lfs.2019.03.055

Zhang, T., Park, K. A., Li, Y., Byun, H. S., Jeon, J., Lee, Y., et al. (2013). PHF20 Regulates NF-Kb Signalling by Disrupting Recruitment of PP2A to P65. Nat. Commun. 4, 2062. doi:10.1038/ncomms3062

Zhao, J., Zhu, J., Lv, X., Xing, J., Liu, S., Chen, C., et al. (2017). Curcumin Potentiates the Potent Antitumor Activity of ACNU against Glioblastoma by Suppressing the PI3K/AKT and NF-Kb/cox-2 Signaling Pathways. Onco. Targets Ther. 10, 5471-5482. doi:10.2147/OTT.S149708

Zhao, Q., Chen, X. Y., and Martin, C. (2016). Scutellaria Baicalensis, the golden Herb from the Garden of Chinese Medicinal Plants. Sci. Bull. (Beijing) 61, 1391-1398. doi:10.1007/s11434-016-1136-5

Zhao, X., Chen, C., Liu, M., Feng, J., Chen, J., and Hu, K. (2017). Remodeling the Blood-Brain Barrier Microenvironment by Natural Products for Brain Tumor Therapy. Acta Pharm. Sin. B 7, 541-553. doi:10.1016/J.APSB.2017.07.002

Zhou, Y., Eppenberger-Castori, S., Eppenberger, U., and Benz, C. C. (2005). The NFkappaB Pathway and Endocrine-Resistant Breast Cancer. Endocr. Relat. Cancer 12 Suppl 1, S37-S46. doi:10.1677/erc.1.00977

Zhou, Y., Wang, Y., Wu, S., Yan, Y., Hu, Y., Zheng, Z., et al. (2020). Sulforaphanecysteine Inhibited Migration and Invasion via Enhancing Mitophagosome Fusion to Lysosome in Human Glioblastoma Cells. Cell Death Dis. 11, 1-16. doi:10.1038/s41419-020-03024-5

Conflict of Interest: The authors declare that the research was conducted in the absence of any commercial or financial relationships that could be construed as a potential conflict of interest.

Publisher's Note: All claims expressed in this article are solely those of the authors and do not necessarily represent those of their affiliated organizations, or those of the publisher, the editors and the reviewers. Any product that may be evaluated in this article, or claim that may be made by its manufacturer, is not guaranteed or endorsed by the publisher.

Copyright $\odot 2021$ Uddin, Kabir, Mamun, Sarwar, Nasrin, Emran, Alanazi, Rauf, Albadrani, Sayed, Mousa and Abdel-Daim. This is an open-access article distributed under the terms of the Creative Commons Attribution License (CC BY). The use, distribution or reproduction in other forums is permitted, provided the original author(s) and the copyright owner(s) are credited and that the original publication in this journal is cited, in accordance with accepted academic practice. No use, distribution or reproduction is permitted which does not comply with these terms. 